\title{
Towards an antifragile urban form: a research agenda for advancing resilience in the built environment
}

\author{
Francesca S. Sartorio ${ }^{1} \cdot$ Patricia Aelbrecht ${ }^{1} \cdot$ Hesam Kamalipour ${ }^{1} \cdot$ Andrea Frank $^{2}$
}

Accepted: 4 February 2021 / Published online: 17 March 2021

(c) The Author(s), under exclusive licence to Springer Nature Limited part of Springer Nature 2021

\begin{abstract}
This paper aims to initiate reflections on what an antifragile (Taleb, Anti-fragile. Things that gain from disorder. Penguin Books, London 2012) built environment might look like by furthering the debate on dynamic non-equilibrium resilience, specifically in terms of scale, urban morphology and social life in urban areas. It will do so by presenting a critical review of relevant literature on resilience in the built environment and linking it to what we know so far about the physical (i.e. geographical, morphological and so on) and socio-cultural conditions that have likely limited the spread of COVID-19 while maintaining quality in urban space in early 2020. As the current pandemic is sharpening our understanding of both the link between local and global action and the power encompassed in the exercise of professional and technical knowledge and practice, the paper concludes with (i) speculations on how the current crisis and its management (i.e. lockdown and social distancing measures in public space' use) might lead to radical changes to the way we think of, and design the conditions for, urban public life and sociability; and with (ii) an agenda for further research on what role urban forms and uses play in speeding or slowing viral spread in different contexts.
\end{abstract}

Keywords Resilience · COVID-19 · Antifragility · Urban form · Research agenda

At the root of every pandemic is an encounter between a disease-causing microorganism and a human being. But that encounter, along with the events that lead up to it and the events that ensue from it, is shaped by numerous other events taking place at the same time - as well as by the weather, the price of bread and ideas about germs, white men and jinns. The pandemic in its turn affects the price of bread, ideas about germs, white men and jinns - and sometimes even the weather. It is a social phenomenon as much as it is a biological one; it cannot be separated from its historical, geographical and cultural context.

Spinney (2017, p.5)

Francesca S. Sartorio

SartorioF@cf.ac.uk

1 Cardiff School of Geography and Planning, Cardiff University, Glamorgan Building, King Edward VII Avenue, Cardiff CF10-3WA, UK

2 School of Geography, Earth and Environmental Sciences, University of Birmingham, Birmingham, UK

\section{Introduction}

The primary aim of this paper is to develop a research agenda to understand how the urban form, and its social uses, likely supports or slows down virus transmission in the 2020 COVID-19 pandemic. Ensuing research will address a number of knowledge gaps contextually: what features of the built environment and associated social behaviours are relevant to disease transmission? And how can the concept of resilience be developed to deal with uncertainties caused by pandemics in urban space? In this, we follow efforts of scholars, who have started to formulate research agendas in cognate areas, such as Salama (2020) and Florida and Pendigo (2020). We reassess and build upon resilience thinking using the concept as a lens to explore the relations between urban morphological issues and sociability anew and providing a critical appraisal of the limitations of the concept in relation to the built environment, specifically by raising awareness of the complementary concept of antifragility. Antifragility overcomes the difficulties inherent in assessing resilience by allowing for more straightforward means of measuring the likelihood that a place can support safe social interactions under unexpected, sudden changes in public life. We believe this can meaningfully contribute to ongoing theoretical 
debates on the role of urban design in supporting public life by presenting an original argument on how antifragile urban forms are needed to underpin resilient societies, of significance and applicability in both the Global North and South.

This paper is structured in four parts. The first summarises recent contributions from disciplines other than urban planning and design on the factors that seem to link COVID-19 spread to spatial features. The second provides a literature review on urban resilience, highlighting its limitations regarding the increasingly complex and multifaceted challenges that cities face, favouring a dynamic non-equilibrium approach and introducing the concept of an antifragile built environment. After reflecting on how the current pandemic is being dealt with in space and speculating on how planning and design might be evolved from the current crisis, the paper presents a research agenda to support the development of an antifragile approach to urban design.

\section{What we (tentatively) know about COVID-19 so far}

COVID-19-related data available to date need to be taken with several caveats. Different countries manage health services and collect data differently; this impacts the reliability of any comparative study. A cursory look at published material shows that much data relate to urban areas; this might indeed be as the disease spreads more in cities or be instead linked to the fact that bigger administrations might be better equipped to gather data. In some countries, positive tests are linked to the administrative area where the patient resides, in others to the area where the hospital or medical practice where patients have been tested is situated. As it is likely that in poorer or more peripheral regions, patients need to travel further afield to get medical attention, impacting in turn, the geolocation of transmission data. Rules guiding testing and resources available might have an indirect role in shaping datasets. Nevertheless, a few considerations can at this stage be assumed valid to start thinking about the relations between the virus and scale, urban morphologies and sociability in cities.

\section{A multi-scalar and multi-systemic phenomenon}

That pathogens and illnesses have intimate connections with the environment they are most closely connected with seems to be widely acknowledged in many fields, from epidemiology to human geography, as is the fact that pandemics have their roots in globalised politics and economics and that they navigate the world at increased speed. New illnesses are most likely zoonotic. These emerge from increasingly aggressive anthropic encroachment on natural habitats when-due to close proximity and risky interactions between farmed and hunted animals and humans-(old and new) pathogens cross species and move from one host to a new, likely defenceless, organism (Spinney 2017). Once the species cross has taken place, cities, as containers for, and enablers of, intense social interactions, provide fertile ground for the spread of what become crowd illnesses. Illnesses develop then alongside the formation of social nuclei and behaviours therein shaping cities: both with the development of new ideas and the implementation of urban change (Morbelli 1997; Spinney 2017).

The increased speed of global movements, supported by technological progress, provides new opportunities to vira. Pathogens make their way from animals to humans locally in rural areas and spread to more urbanised regions thanks to global networks moving large numbers of people, animals and goods quickly across the globe on a daily basis (United Nations 2020; Ghosh et al. 2020). Viewed from this angle, beyond its novelty, COVID-19 does not look exceptional; neither in its ability to spread in space nor in terms of the speed it travels.

\section{COVID-19 adapts to social and spatial morphologies}

While liminal anthropic/natural spaces provide the opportunity for pathogens to jump from species to species, more urbanised areas - as the places where societal exchanges are concentrated - create favourable conditions for crowd illnesses to develop alongside their hosts and become successful (WHO 2020, p. 4). COVID-19 is an airborne virus and, while able to affect most organs in the body, its statistically more visible damage relates to the respiratory system. Exposure to high levels of pollution extended over time has been found to have a strong correlation with higher COVID19-related death rates (Wu et al. 2020; Conticini et al. 2020; Travaglio et al. 2020). A study looking at 66 administrative regions in European countries suggests that the majority of deaths (78\%) occurred in the 5 regions with the highest nitrogen dioxide pollution (Ogen 2020). Nitrogen dioxide is the result of fossil fuel combustion; the levels indicated as associated with increased COVID-19 lethality are rarely associated with single sources of pollution and more often the combined result of mobility, individual and collective energy consumption and heating choices; the pollutant trademark of urban living in the modern world where energy transition has not quite taken hold yet. The concentration of people is correlated to higher incidences of COVID-19 transmission, but density alone is insufficient in explaining why the disease has spread more in urban areas as a whole, and in some more than others (Fang and Wahba 2020; Hamidi et al. 2020; Larsson et al. 2020, p. 19). Morphologies, however, might play a role here. Ogen (2020) mentions that geographical and geological features in Wuhan, Milan and Madrid limit natural airflows and particles dispersal. While some exploratory work on urban morphology (e.g. Sennett 2020) seems to support the relevance of macro-analytical dimensions, such as density, in determining transmissions, other datasets (e.g. ATM Milano Citta' Metropolitana, 2020) seem to suggest that while dense structures 
and well-developed transport systems provide support for the spread, actual hotbeds develop in less dense residential fringes rather than mixed-use centres, warranting further research on micro-analytical dimensions.

In addition to the shape and size of urban conurbations, social dynamics and interactions that take place within them seem to play a role. Coronavirus lethality has been shown to have a correlation with social deprivation, with Black and Asian ethnic origins (in some European countries and the US), and with lower skills jobs (see, e.g. ONS 2020a, b; Larsson et al. 2020, p. 5). For planners, this is another signpost; social and ethnic diversity-and the emerging pockets of deprivation-being also eminently urban characteristics in both the Global North and South. Deprivation and lower skillsets, as well as minority ethnic groups, come in even stronger relief in contexts characterised by the shortage of basic infrastructure and sanitation (World Bank 2020), particularly in situations exacerbated by extreme poverty, overcrowding and containment (Truelove et al. 2020). Inequalities and deprivation exist in most cities globally while cultural features and urban sociability-and the spaces containing them-may differ considerably in different places. COVID19 prompts us to focus on both differences and similarities: human interactions, their material settings and cultural differences across different contexts; all need further investigation.

\section{Urban social behaviours have micro-spatial implications}

Things might not get back to a pre-pandemic 'normal' until an effective vaccine is developed and so a 'new normal' with respect to public life and social interactions, adopting physical distancing and other public health measures-as well as accepting a drift to and from more or less strict forms of controls-will have to take hold for the next 18 to 24 months (Pueyo 2020). Controls so far have ranged from measures ensuring distance between people can be kept at all times, to wearing face coverings and various other measures preventing human mixing and interacting in physical proximity affecting all or parts (e.g. the elderly; those who travel and so on) of society (Larsson et al. 2020). In addition to impacting the economic system, mental health, livelihoods and life styles of many (OXFAM 2020), these controls profoundly affect life in public urban places.

To model the reproduction rate (the R-number guiding government's stricter or loser isolation regimes) of a virus in time (Kucharsky 2020), statisticians use the concept of DOTS (Duration, Opportunity, Transmission and Susceptibility). Duration (D) refers to the time period individuals are likely to spread infection. While (D) is linked to the type of virus, and Susceptibility (S) to populations' vulnerability (lack of immunity) to the specific disease, there are features of urban areas that are likely to affect the Opportunity (O) for transmission and the behaviours that lead to Transmission (T). According to Kucharsky, $(\mathrm{O})$ is the measure specifically related to social behaviours and is likely subject to cultural variations. ( $\mathrm{T}$ ) is also likely to be affected by behaviours, to an extent, as it refers to the chance of the virus crossing from individual to individual through interaction. Planning the city focuses on producing spaces that enable public life; it is a practice shaped by culture and societal attitudes. Much infection is likely to spread in private spaces, but a better understanding of how urban morphology and uses are likely to affect $(\mathrm{O})$ and $(\mathrm{T})$ might support an interdisciplinary approach towards developing spaces better suited to safe social interactions, both in the spirit of limiting the spread of future pandemics and — if and when they struck—improving life quality maintaining physical separation.

Emerging geographical studies look predominantly at macro features of urbanised regions and often fall short in addressing the micro-features likely to directly shape social behaviours. A closer look can sharpen our understanding of aspects of the built environment relevant to disease transmission as, ultimately, it is how people behave that will dictate outcomes. We can hypothesise that cultural habits related to personal space, for instance, and socio-economic spatial structures are as likely to have an impact as macro features (i.e. density, geography and so on). The micro-spatial features are likely to be more relevant in directly affecting $(\mathrm{O})$ and $(\mathrm{T})$ : e.g. the width of pavements might be relevant in spacing or pushing together pedestrians; road design is likely to influence daily transport choices, the combination of uses within blocks and individual buildings will underlie the potential for temporal overlaps, and lower or higher densities at any given time, of users in specific open or enclosed spaces; public space qualities, shape and distribution, associated with local mores, are likely to support specific types of sociability and discourage others. There are features worth exploring because they might indirectly relate to the likelihood of the virus reproducing too. The virus seems to be potentially more lethal when affecting individuals with a variety of preexisting conditions (Larsson et al. 2020), and some are starting to see syndemic features (as in Singer 2009) in the COVID19 global spread. For example, (S) to COVID-19 is currently assumed $100 \%$ as only a minority of the population presents antibodies. Fatality is calculated somewhere between 0.5 and $2 \%$ of infections. Although high levels of pollutants and poverty are unlikely to affect (S), they seem to have a role in increasing fatalities amongst those infected, putting in sharp focus health inequalities within populations. Also, lower-skill jobs might correlate with higher numbers of infections due to frontline workers being more exposed than others to the virus and therefore have increased $(\mathrm{O})$ and $(\mathrm{T})$.

\section{Perceptions of safety and risk and behaviours in public space}

As many COVID-19 control strategies introduced by governments rely on individuals' actions, perceptions of safety 
and risk are as important as actual safety in determining behaviours. According to Dryhurst et al. (2020, p. 2), far from being objective,

a large body of research over the last decades has shown that risk perception is a subjective psychological construct that is influenced by cognitive, emotional, social, cultural, and individual variation both between individuals and between different countries (Douglas and Wildavsky 1983; Loewenstein et al. 2001; Leiserowitz 2006; Joffe 2003; Kasperson et al. 1988; Sjoberg 2002; Wildavsky and Dake 1990; Slovic 2010; Slovic, Fischhoff, and Lichtenstein 1982; van der Linden 2015, 2017; Wåhlberg 2001).

Risk is 'socially negotiated' and based on people's experiences, values and trust in institutions (Rickard 2019, as in Dryhurst et al. 2020, p. 10): the variables differ by countries and cultures but, generally, perceptions seem highly influenced by individuals' experiences and worldviews as well as their immediate environment (Dryhurst et al. 2020). Behaviours are in turn affected by knowledge and understanding of risk; trust in government seems key (Seale et al. 2020; Tran and Ravaud 2020), but it alone does not link directly to compliance, as too much trust in government's intervention might lower individuals' risk perception and hence impact on rule compliance (Wong and Jensen 2020, p. 9). Misinformation circulated online can potentially impact trust in government guidance (Krause et al. 2020; Geldsetzer 2020) and consequently on adherence to rules. Illustrative examples are the contested adoption of face coverings and social distancing measures with uptake depending on social groups (Williams et al. 2020) and attitudes aligning with political positions (Rothberger et al. 2020).

The built environment also influences behaviours in public space. One strand of environmental behavioural studies (Barker 1968; Bechtel 1997; Bechtel and Churchman 2002; Gifford 1987; Lee 1976; Lynch 1960; Mehrabian and Russell 1974; Porteous 1977; Proshansky et al. 1972; Zeisel 2006) posits that individuals' behaviours cannot be explored in isolation from related settings. Recent research shows that the built environment can shape emotional responses (Weinreb and Rofè 2013; Pykett et al. 2020) and affect behavioural responses to emotions such as joy or stress (see e.g. Hollands et al. 2013). Alterations and adjustments of public space have as much influence in changing social behaviours as individuals' perceptions of risk and safety therein. Social encounters, 'making' the city (Massey 2005) and giving it 'its distinctive character' (Wilson 2017, p. 452), are being impacted by current divisive discourses related to the pandemic as political and social identities have become more visible through choosing to adhere to or disobey COVID-19 mitigating rules. The shape of the built environment can help us negotiate differences or exacerbate conflict and take itliterally - to our streets (Valentine 2008; Valentine and Waite 2010). Urban design can play a pivotal role in favouring or hindering possibilities: by helping to carve individual routes in the 'new normal' or constrain and limit choices, by affecting stress levels or providing space for release.

While a lot about the virus is still unknown, the tentative understandings we have suggest that COVID-19 seems a formidable agent in crossing scales and systems: moving from species to species, from rural to urban areas and from the periphery to the centre. Having developed in close relation with its human host, we could say that it is, to an extent, co-constitutive of social behaviours and might contribute to shaping social nuclei in the future. The virus makes us visualise more vividly than before the role, extent and speed anthropic systems have in shaping our planet. It makes us 'see' with unprecedented immediacy how cities are microcosms encompassing systems and scales extending in space and time. It brings into focus the relevance of local cultures and the historical layering of spatial features in the built environment that shape contemporary forms of urban sociability. Adopting a multi-scalar approach and focusing on morphological issues as well as behaviours and cultural mores might open a novel angle to understand how spatialised social behaviours underpin the virus' spread and might provide fertile ground to inform public health solutions.

\section{An antifragile built environment to support resilient cities}

While it seems that urban environments are often unsuitable to limit the spread of viruses or guarantee a reasonable quality of life when a lockdown is called, a debate is ripe as to what sort of urban life COVID-19 will leave behind. Many cities worldwide have developed temporary measures to enable socially distanced public life and some have started thinking about ways to become more resilient to future pandemics. Resilience is a relevant concept to investigate aslike viral diseases-it encompasses natural and anthropic systems and scales extending in space and time.

The body of literature on the topic is vast; the Resilience Alliance's multidimensional definition of the term is amongst the most popular:

Resilience, as applied to integrated systems of people and the natural environment, has three interrelated characteristics: the amount of change the system can undergo and still retain the same controls of function and structure; the degree to which the system is capable of self-organization; and the ability to build and increase the capacity for learning and adaptation (Marcus and Colding 2014, p. 56).

An array of fields and disciplines have used and developed the concept of resilience in different ways. The table below attempts to summarise the scholarship, albeit it does not do justice to the richness of the resilience debates and interpretations. Nonetheless, it paves the way for the arguments we are pursuing. 


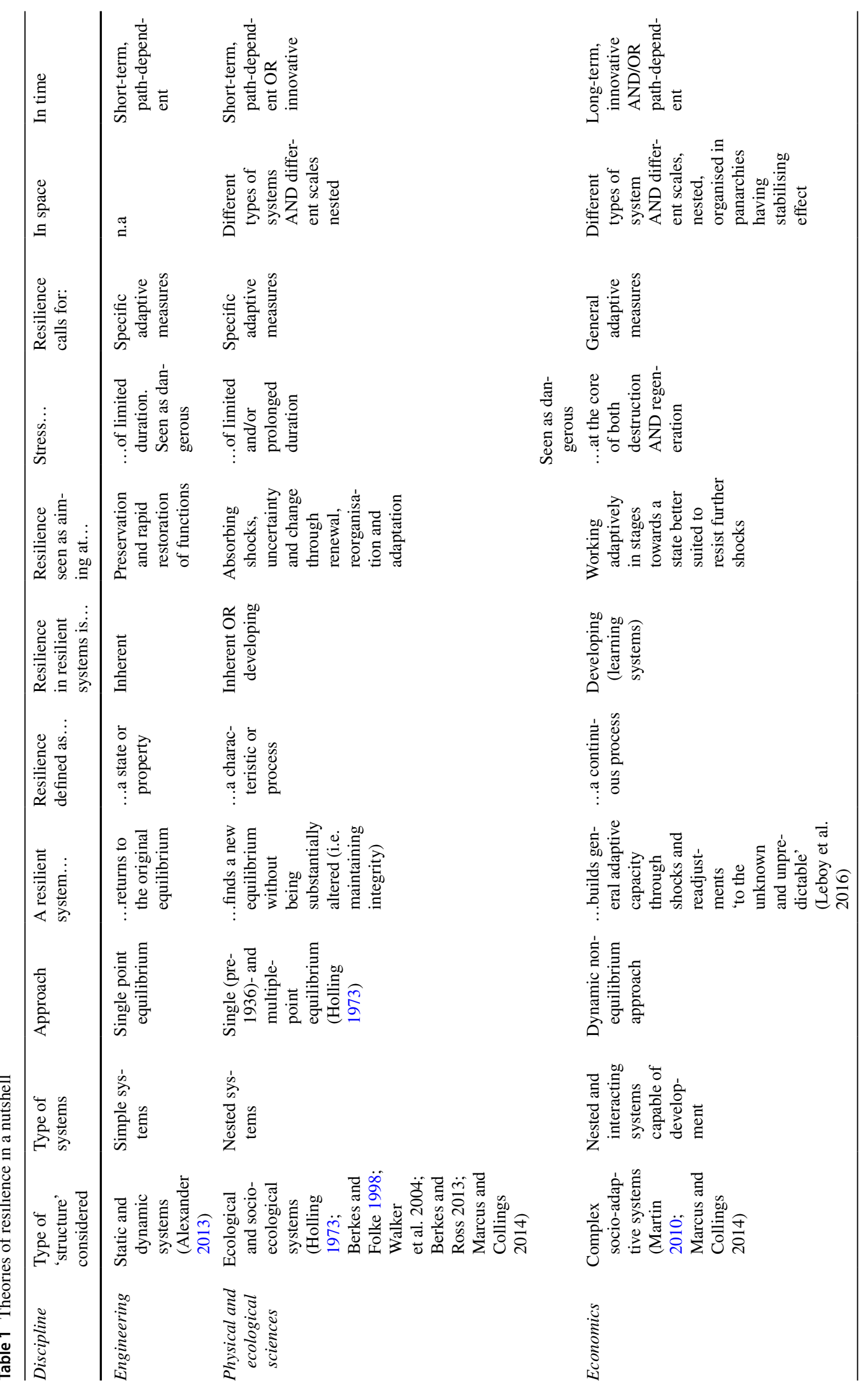




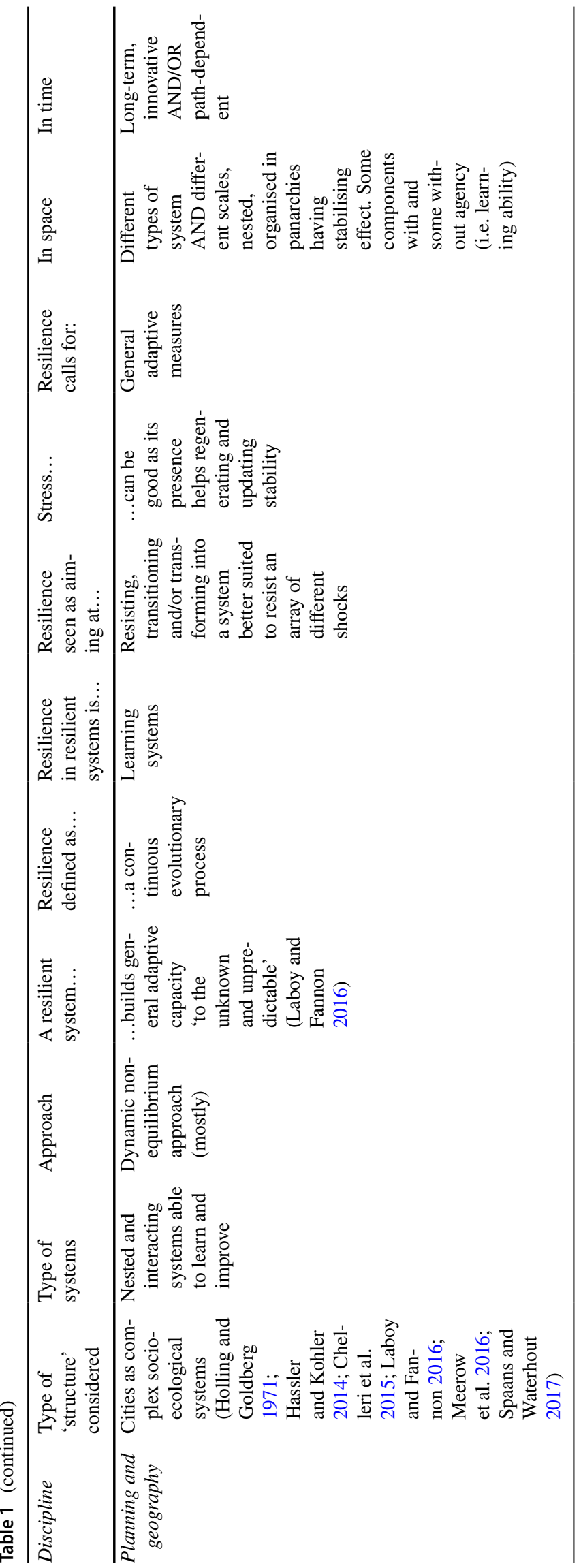

The literature is diverse, but aligns when defining resilience as a systems concept (e.g. Berkes and Folke 1998; Berkes et al. 2003; Berkes and Ross 2013, p. 14 as in Alexander 2013, p. 2711; Marcus and Colding 2014). Studies of urban resilience see cities as near-paradigmatic socioecological systems: embedded, interscalar, internally interrelated and complex: 'a spatial mosaic of social, economic and ecological variables that are connected by a variety of physical and social dispersal processes' (Holling and Goldberg 1971, p. 227). Cities are part, and embedded within, panarchies expanding in time and space (Marcus and Colding 2014; Hassler and Kohler 2014). The size of panarchies is important (Meerow et al. 2016; Spaans and Waterhout 2017; Laboy and Fannon 2016). A good mix of systems and resources supports creative development yet, beyond a certain dimension, systems lack flexibility and are less able to cope with shocks (Hassler and Kohler 2014, p. 122). The interconnectedness amongst systems is relatable to the multiplicity of stresses impacting cities and acts as a stabilising net for its components. While earlier approaches considering single- or multiple-point equilibria as final goals for resilient systems see value in specific measures for adaptation (e.g. Alexander 2013; Meerow et al. 2016; Holling 1973; Walker et al. 2004), the dynamic non-equilibrium theory focuses on features conducive to general adaptive capacity (from now on GAC) (Meerow et al. 2016; Laboy and Fannon 2016; Martin 2010; Hassler and Kohler 2014). Within recent developments in systems' thinking, resilience is seen as a continuous process of change and progress, in many ways evolutionary (Folke et al. 2010), led by systems with agency and capable of learning. For learning to take place, and systems to evolve, time is crucial (Chelleri et al. 2015; Davoudi et al. 2013; Meerow et al. 2016; Laboy and Fannon 2016) as there might be interrelated short- and long-term responses developing and path dependency (Martin 2010; Laboy and Fannon 2016).

While resilience as defined above can be used as a lens to understand urban societies, economies and cultures, it is a difficult concept to support the study of the materiality of the built environment. Bruneau et al. (2003) and Tierney and Bruneau (2007) suggest four domains of resilience in human systems: technical, organisational, social and economic. The technical domain-subsuming the material elements-is inherently different from the other three as it is unable to enact change by itself. Arguably, there are specific urban forms that might be more suitable to be changed over time and sustain the adaptation required by a resilient 
society within a socio-ecological system. Bosher (2008) talks of 'built-in resilience' as a material quality to keep adapting. Similarly, Taleb (2012) introduces the concept of a theoretical quality of a structure held a priori to respond to a stressor positively, and to thrive on the score of shocks and calls this quality antifragility. If fragility is the characteristic of something that suffers from the variability of its environment (e.g. a porcelain cup), robustness an ability to resist shock (e.g. a plastic cup), antifragility refers to an ability to benefit from instability (Taleb and Douady 2013, p. 1677), e.g. akin to the human bones' ability to get stronger and denser the more they are subject to impact. Like resilience in the dynamic non-equilibrium approach, 'antifragility has a singular property of allowing us to deal with the unknown, to do things without understanding them-and do them well' (Taleb 2012, p. 4). Fragility and antifragility as characteristics are both mathematically modelled as non-linear responses (Taleb 2012, pp. 12-13) to the 'disorder family' (which includes uncertainty, variability, imperfect knowledge, chance, time and dispersion of outcomes amongst others). Antifragility is a characteristic pre-existing the stressor, so it is not developed in the process of change. Although ' $[\ldots]$ socio-ecological resilience theory understands systems as constantly changing in non-linear ways [...]' (Tyler and Moench 2012 as in Meerow et al. 2016, p. 39) too, resilience as the ability to develop GAC 'to the unknown and unpredictable' (Laboy and Fannon 2016) implies the existence of a system capable of progressive intelligent steering, while antifragility embodies flexibility and an inherent ability to mutate that is designed into a setting and that can be accessed at various points, with different aims. Blecic and Cecchini (2020, p. 178), building on the concept in the context of planning, add that 'antifragility is promoted by whatever opens and increases the possibility of local experimentation and tinkering, of new combination of uses in relation to new demands and pressures, of learning from trial-and-error' and stress the importance of optionality and of reducing asymmetries in antifragile systems. On the whole, antifragility appears a fruitful concept to extend urban resilience theories while investigating the built environment. Antifragility allows to recognise the inertia of material structures and helps to unravel the physical substrate from much of the complexity that resilience studies have presented so far. It acknowledges the links between materiality and the socio-ecological systems it is part of. Its deployment in the study of GAC might potentially provide a more readily usable contribution to practice as while stress and risk are difficult to anticipate (yet required to be modelled in the study of resilience), antifragility (like fragility) can be simply measured (i.e. are 'non-predictive; Taleb 2012 , p. 8) avoiding the high risk related to attempting predictions in uncertain and unstable conditions.

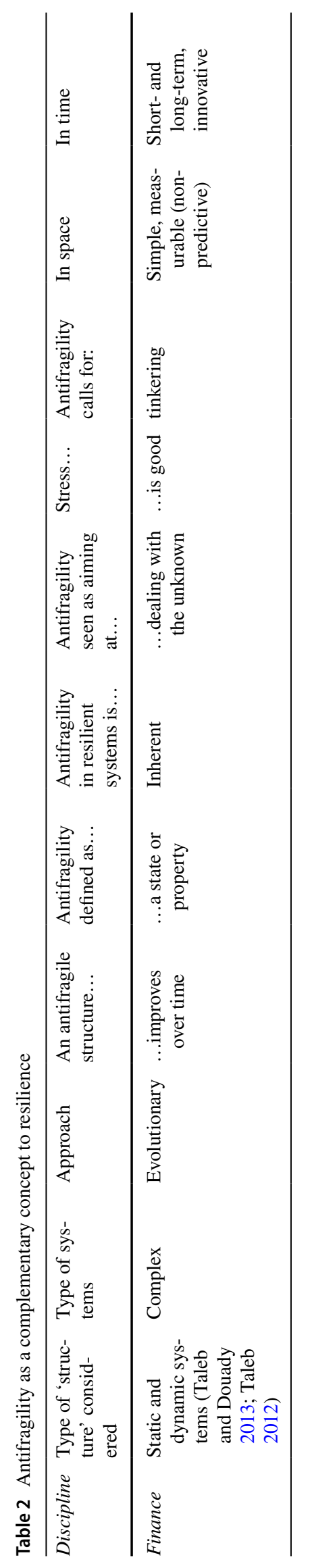


It seems an apt moment to add antifragility to the study of dynamic non-equilibrium theory as the concept of resilience is only starting to be used in relation to pandemics. Despite having often been used in planning (e.g. when exploring sudden shocks) and in connection with longer-term processes (such as sustainability and climate change; Coaffee 2013), resilience might need to be revisited to deal with what is a much more complex and multifaceted phenomenon (Bliss 2020 citing Berkowitz 2020) than others before. Resilience, seen as developing GAC within an evolutionary multi-scalar systems concept, might provide a useful analytical frame when complemented with antifragility whereby (a) resilience is used as a lens to study features of systems and panarchies capable of steering and agency (e.g. community; economics; governance; etc.) and (b) antifragility is used to understand the material, inert elements of the systems (e.g. spatial settings; morphological features; etc.). Although we know still little about COVID-19, we can see that the pandemic lends an interesting research angle linking micro-level spatial analysis and behaviours.

It is worth noting that resilience is multifaceted and controversial in its use (Spaans and Waterhout 2017; Meerow et al. 2016; Alexander 2013; Hassler and Kohler 2014; Davoudi et al. 2013). The shift from using it mainly as a descriptive and analytical tool to becoming a normative construct proved particularly problematic not just because the concept in itself becomes 'imprecise, contradictory and subject to negotiation' (Hassler and Kohler 2014, p. 119) in its practical use but also because-in a world where resources are unequally distributed - the conservative suggestion that a return to pre-existing orders would be unquestionably desirable does not always constitute an entirely acceptable aspiration. For example, as social order is not based on consensus but is the result of power (Alexander 2013), the question of 'what resilience should be pursued, and how' (Pizzo 2015, p. 136) and 'for whom' (Davoudi et al. 2013, p. 306) arises. In this paper, we build on the concept of resilience by coupling it with antifragility and use both as analytical tools. We also consider power in the following sections.

\section{Cities after COVID-19: towards a GAC approach}

Looking beyond the pandemic's causes, new forms of social life, citizenship and community have emerged in the past nine months. Many aspects of our lives have moved online when human interaction and networks of support have been crucial. For some, the transition has been easier; others have suffered forced isolation nevertheless. Although social media can offer a means of extending an otherwise limited social life, many are craving physical presence and interactions.

\section{The pandemic in space: the materiality of the city and path dependency}

While cities' buildings and infrastructure have overwhelmingly proven inadequate and inflexible to enable quality of life since the beginning of the pandemic, they have not changed substantially in the relatively short period since the outset of COVID-19 and-where change has taken placethis has been via 'soft' temporary adjustments constrained by materiality (i.e. path-dependent), such as enlarging pedestrian and cycling paths clawing space usually allocated to motorised traffic (see also Larsson et al. 2020). Table 3 presents a first attempt at cataloguing settings that have come to the fore for both new (post-pandemic) and displaced (prepandemic) social habits. It has been composed based on the authors' personal experience as well as monitoring of media coverage and online repositories of relevant grey literature dedicated to urban design and the city (between February and October 2020); primary sources have been the Guardian (UK and US Editions), The Conversation (the COVID19 and Cities sections), the WBUR website (the section on 'Cities that heal: how the coronavirus pandemic can change urban design'), the Frankfurter Allgemeine Zeitung (in particular the section 'Deutschland in der Pandemie'), the High Street Task Force (the COVID-19 section), C40 Knowledge (the COVID-19 Portal) and Medium (e.g. Nathan 2020). The choice of sources mirrors the authors' personal trajectories in making sense of the times we are living in. While by no means exhaustive, the table provides a snapshot at a specific point in time in the process of rapid urban change as well as a stepping stone in the development of a research agenda.

Change appears strictly path-dependent in the short term with few, if any, initiatives exhibiting radically innovative interventions. Space availability/redundancy, public ownership, flexible layouts, grey areas and transitional spaces seem to have provided the best opportunities for flexibility and short-term successful spatial adaptations.

\section{Behaviours and power: top-down vs. bottom-up approaches}

What has substantially changed is behaviours; these have almost invariably been driven by fear. If 'cities are made of desires and fears' (Calvino 1972) in ordinary times, then fear seems to become the main agent shaping social behaviours 


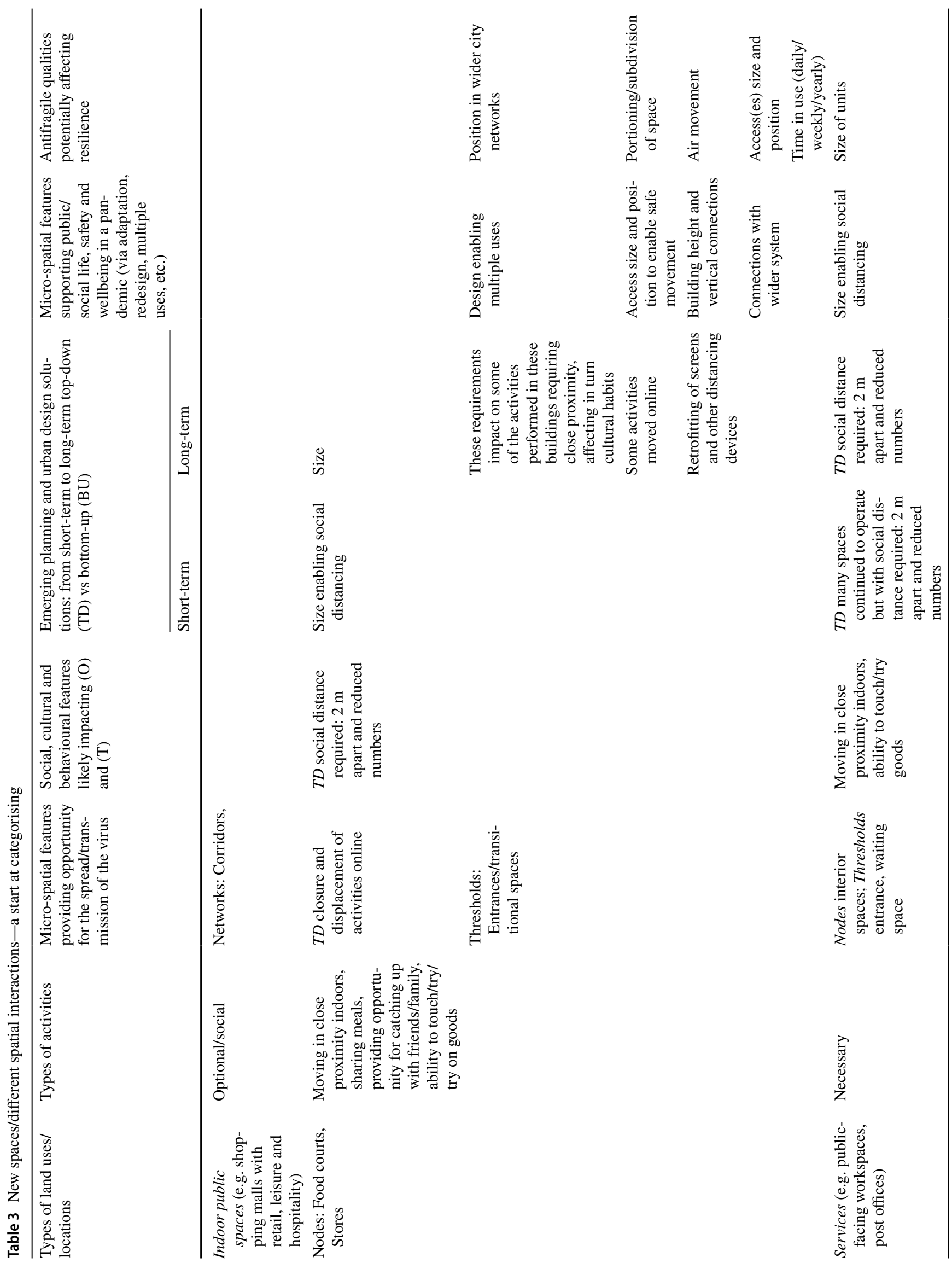




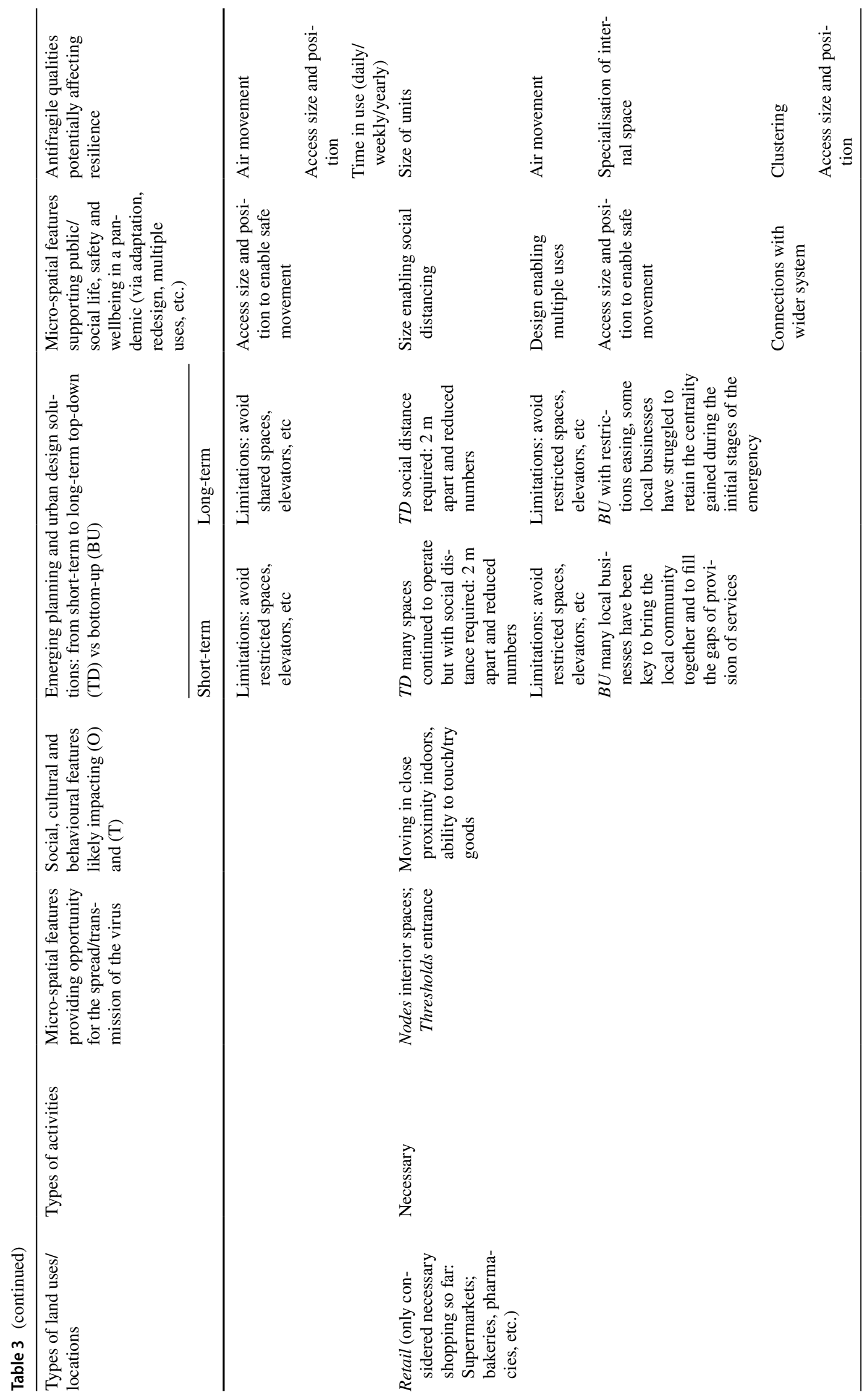

桨 


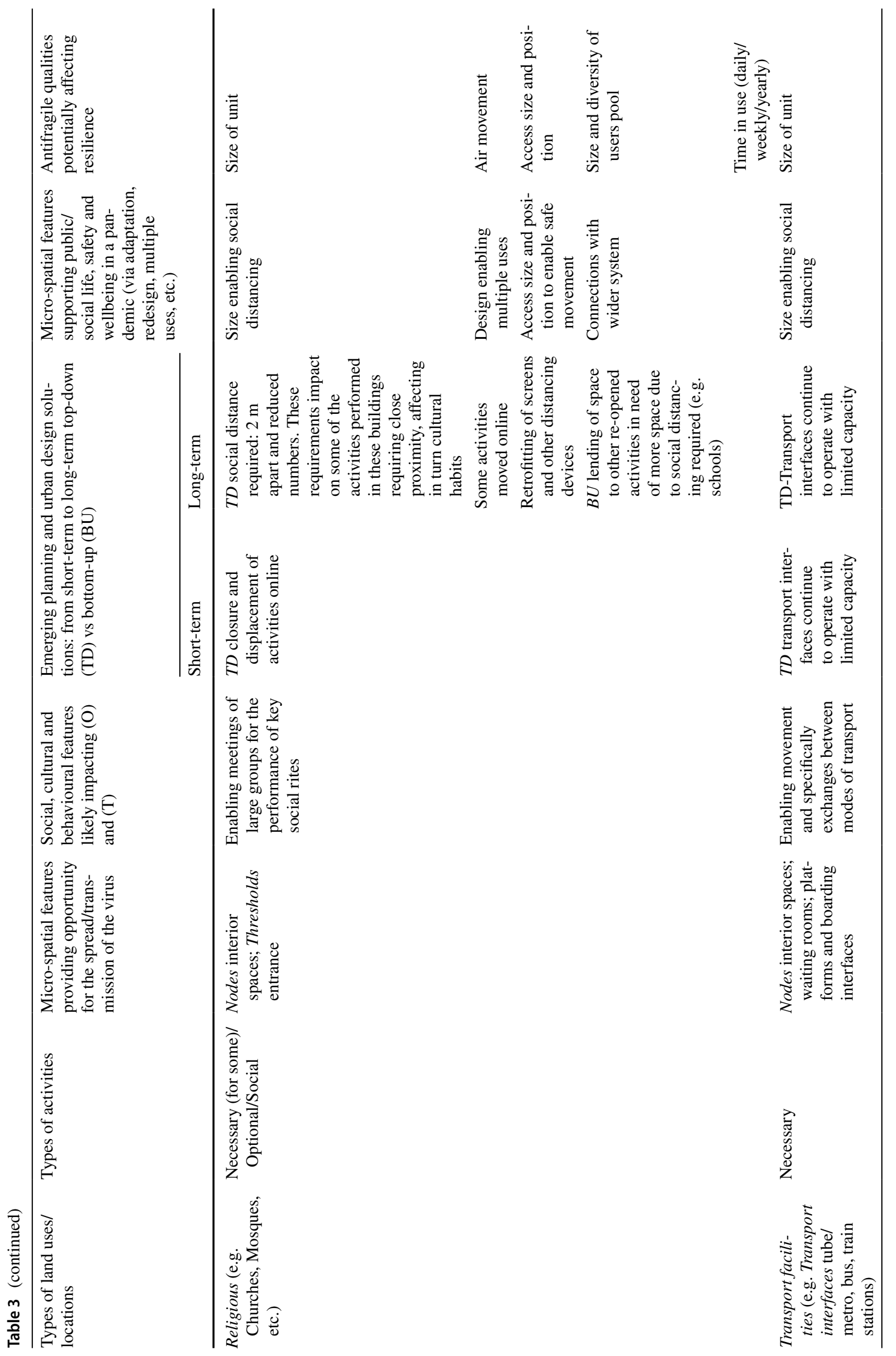




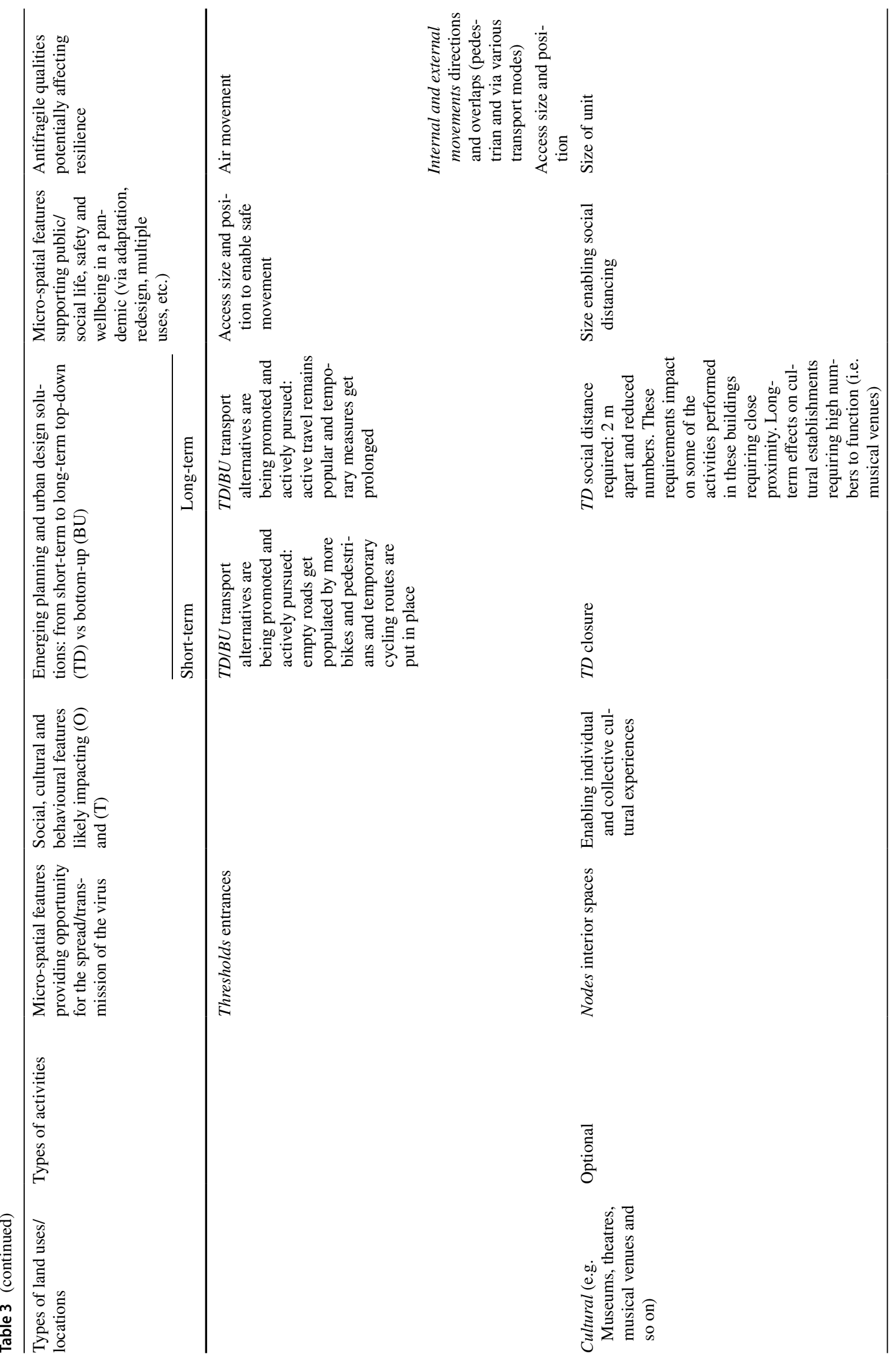

桨 


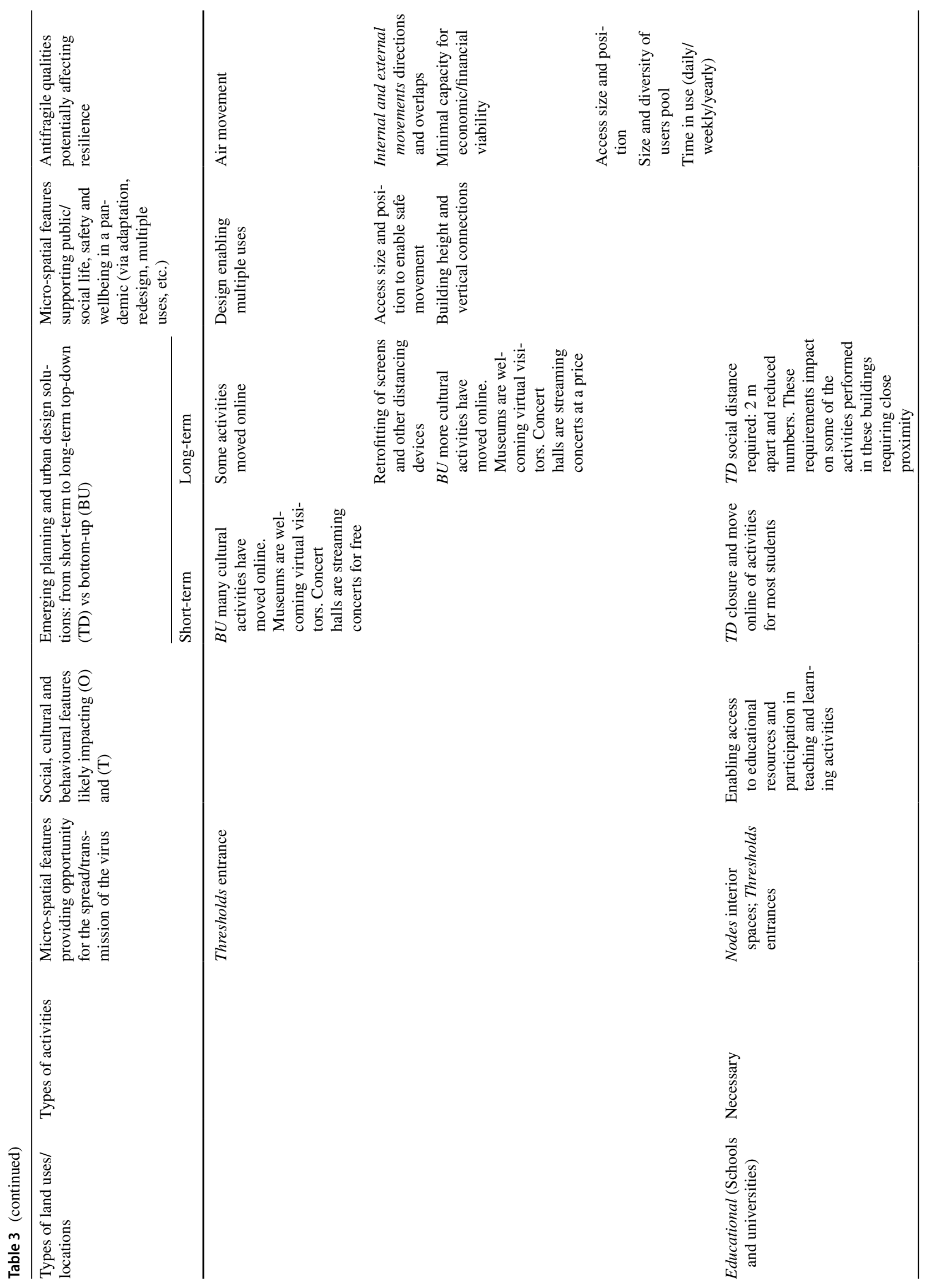




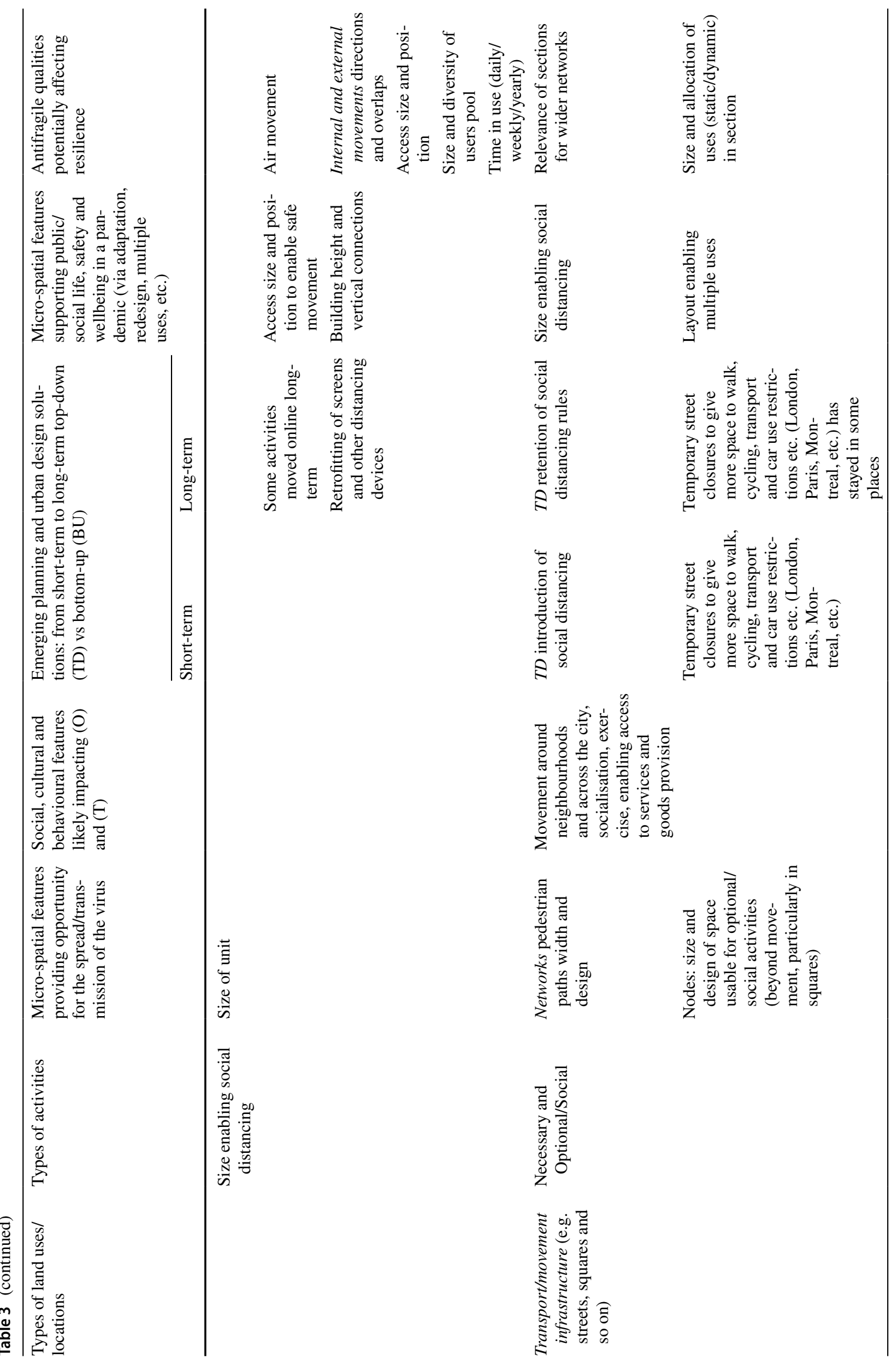

然 


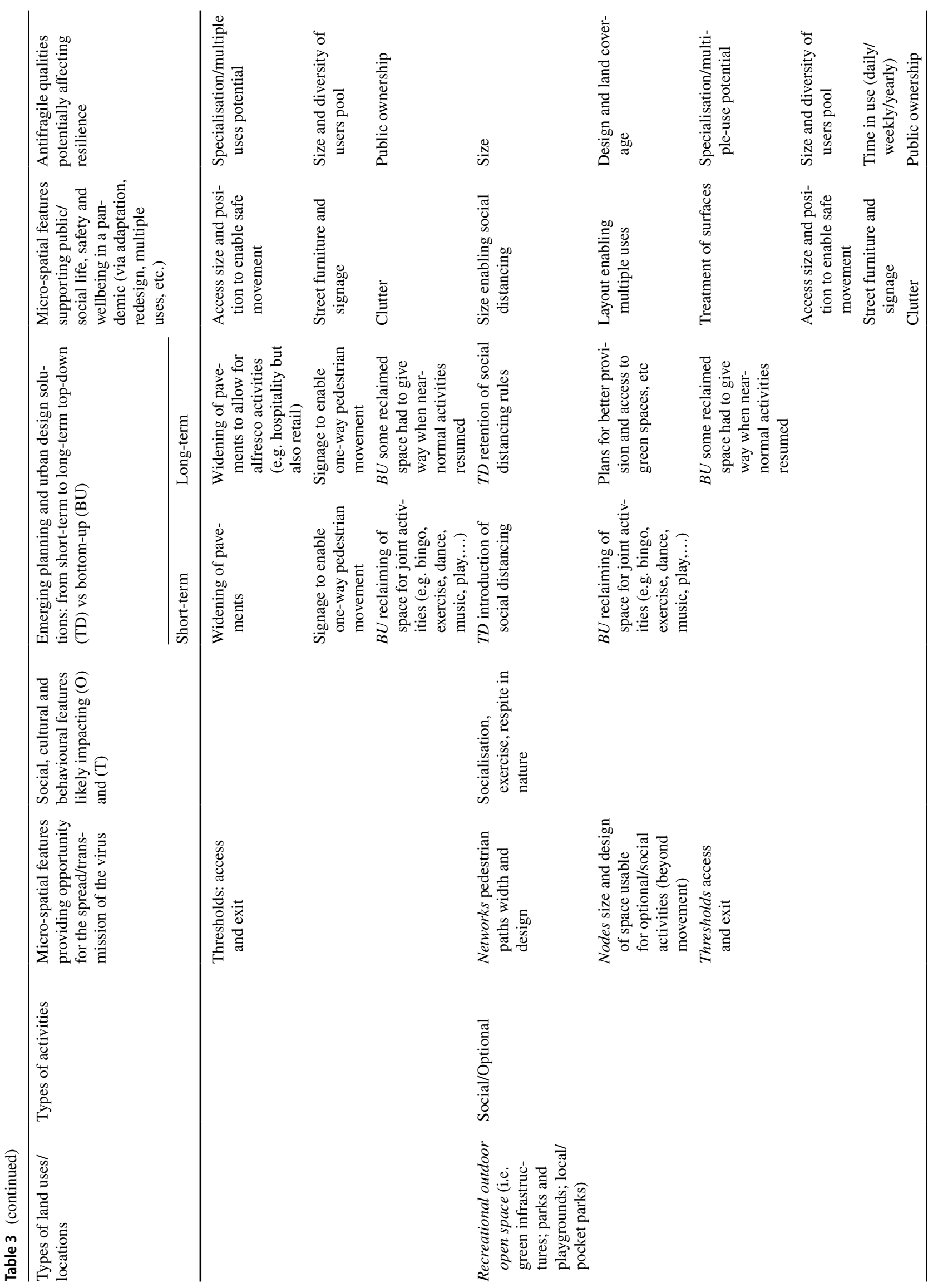




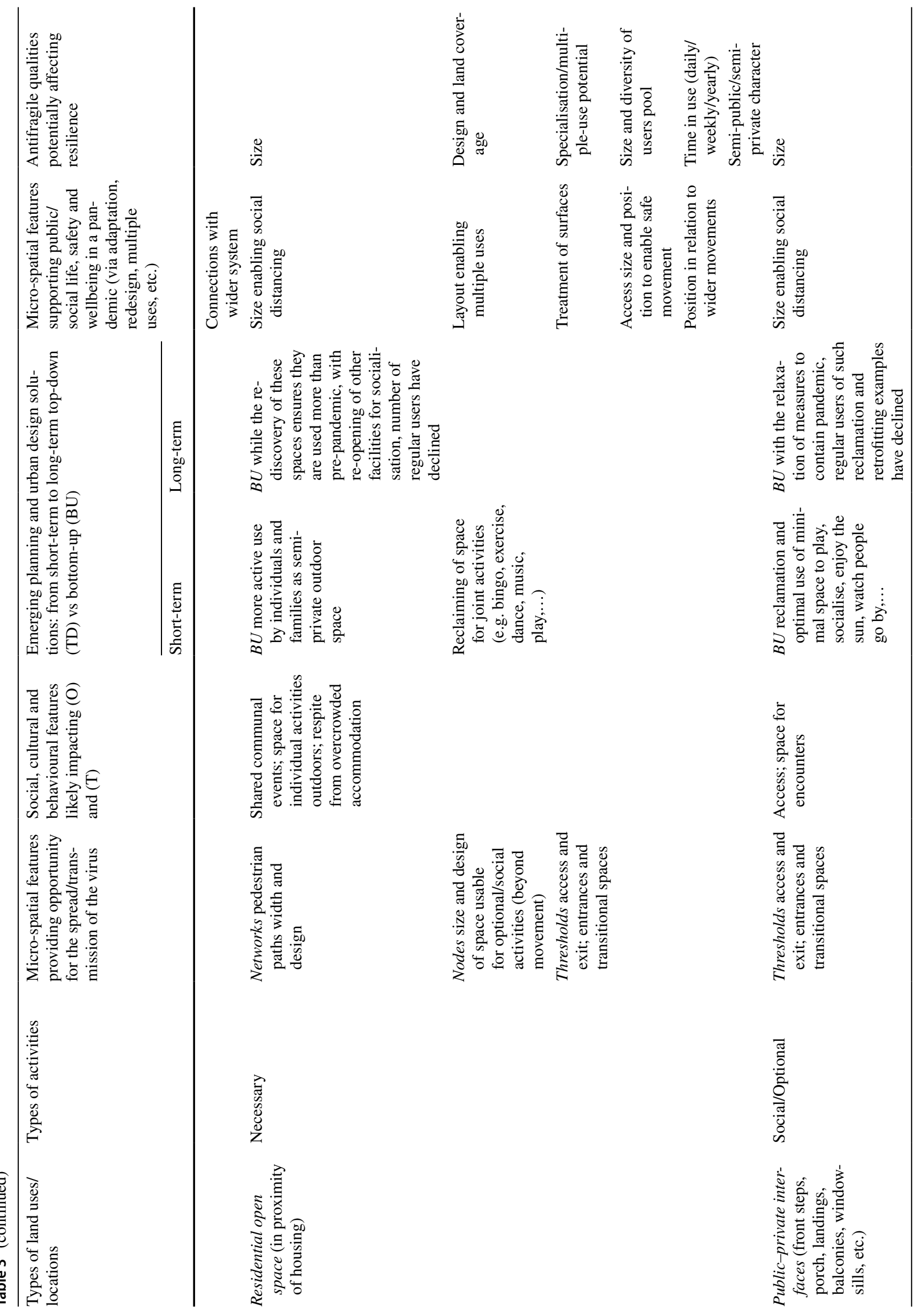

桨 
Towards an antifragile urban form: a research agenda for advancing resilience in the built...

151

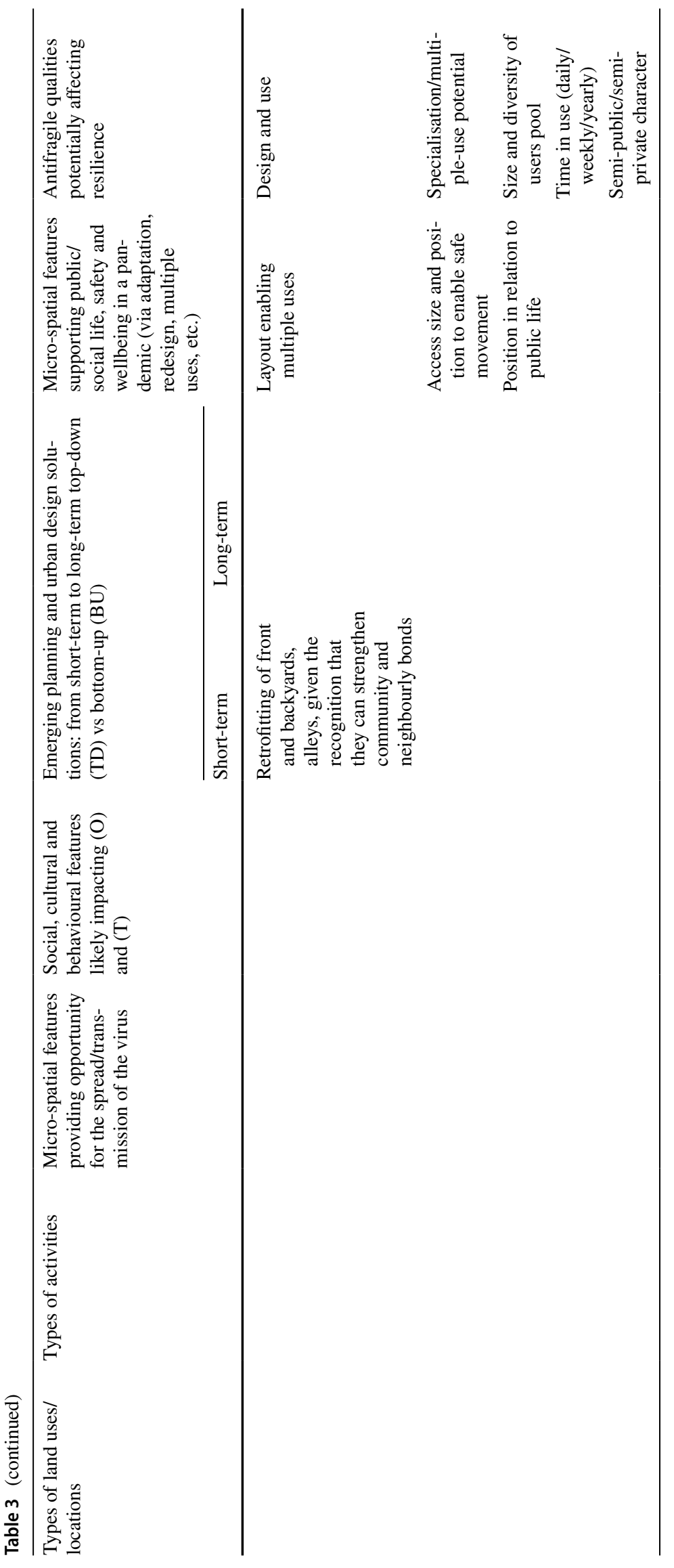


in pandemic times. Behavioural changes dictated by fear of virus spread originated at different levels. Government interventions such as lockdowns and stay-at-home policies radically changed sociability: from restricting what can be done in public to defining one's 'unit' of belonging (not necessarily family or friends anymore, but possibly neighbourhoods as movements were often limited by distance). For these measures' success, trust is crucial; without trust, they are very fragile (Taleb 2012, p. 5). Such measures were introduced (and often strongly enforced) in a top-down manner, with urgency and little to no consultation. Governments also enforced top-down large-scale strategic adaptations of urban infrastructure: London, Paris and Montreal took the lead by pedestrianising entire city centres and creating new, albeit-for now-temporary, cycle routes.

Social behaviours have also been shaped from the bottom-the changes linked to the cumulative effects of individual shifts in shopping and transport habits are a case in point. Reasons to get out have deeply changed; the longdecried attitude of seeing citizens as consumers in their use of city centres, for example, has disappeared globally within a few weeks and the forced isolation has made us all crave interactions. Bottom-up interventions tended to be more creative and innovative-if small-scale and tactical-with people reclaiming streets to create playgrounds for children, to socialise and exercise (see: Daly et al. 2020). Types of interactions have changed too, particularly in space, as everything has to take place at a distance yet, previously separate places (workplace, home, leisure places) have merged into one single space. Chance encounters shape our 'physical' social life as each of us is more bound by place (as opposed to being guided by time) and access to family and friends is limited; this makes the city and its public space more relevant to each of us than ever before. The type of spaces we have been populating has changed dramatically: local squares and pocket parks filling at the expenses of city centres; pavements once used for swift walks now the setting of many different types of interactions (e.g. doorstep dropping of groceries and vigorous hand clapping; conversations through windows; sunbathing on kerbs). These changes are a hidden cry for measures to support 'sociable distancing' (Mehaffy 2020) and improve mental and physical wellbeing. Settings allowing for bridging between the private and the public have proven successful, as have more 'permeable' public-private interfaces, entailing doorsteps, canopies, porches, balconies, courtyards and the like (Banai 2020, pp. 2-3). Semi-public and semi-private spaces such as inner courtyards, entrance halls and stairwells in apartment blocks have become popular places of safe conviviality, hosting bingo evenings, quiz nights, exercise classes and pre-dinner aperitifs without impinging on personal space.

\section{Multi-scalar embedded systems}

Forced permanence made us all look harder at the here and now and appreciate the detail in urban design, and the meaning of proximity, anew: our place being part of a wider network of places closely interconnected. Sudden realisations of geographic distances emerged with the increasing difficulty of reaching familiar destinations in the context of the COVID-19 emergency, and with experiencing first-hand how systems (of food and health provision, for example) that serve us all locally are linked into an economic supply chain straddling the globe, where the very local relies on the wide and far-but not in traditional hierarchies. Dependency on limited supplies made us realise our place in the world, but also, unexpectedly, prompted smaller systems to step up to fill the failures of the big ones; local institutions and businesses often making up for the gaps in provisions from usually bigger providers. Behind such fundamental changes from below and draconian top-down measures, pivoting on individual choices is the acknowledgement that, before the pandemic, city development and management had left cities ill-equipped to cope with crowd illnesses viral spread. Despite Patrick Geddes' early call to 'act locally, think globally' and recent World Health Organization advice specifically for reducing pandemics impact (WHO 2020), most planning and urban design practice today fails to take into account measures with more-than-local effects and respond to a fragmented approach to managing urban features (see also Banai 2020, p. 1) which leaves localities unable to resist and/or swiftly recover from major crises (e.g. earthquake, floods, pandemics and so on), the more so when different threats are combined.

\section{The pandemic in time: temporal adaptations}

COVID-19 has brought about a temporal as well as a spatial epiphany. The sudden need to retreat in our homes was dictated primarily by the fact that — prior to the pandemic —our cities lacked preparedness for life to continue as normal. The long days home, as well as having difficulties every time we stepped out — constantly getting up/down kerbs, circumnavigating parked cars, having to step into the road in order to have a distanced doorstep or pavement conversationbrought about the realisation that measures that could have made us healthier and safer beforehand might have improved the quality of our lives in lockdown too. The city we have needs considerable stretching, often showing at the seams, to support spatial and behavioural adjustment. Adaptation of public open spaces has taken place quicker than change in the built environment, e.g. through measures that have seen restaurants and shops spill out onto pavements, on tables and stalls, allowing safe dining and socially distanced queuing. 
Existing urban morphologies can potentially accommodate a range of activities and uses over time. Changing functional mixes by adapting existing urban morphologies can potentially provide more equitable access to urban amenities with walkable catchments. It appears now critical for urban design and planning to move beyond prescriptive practices of regulating space to incorporate the temporal dimension and focus on how places can perform over time. Behaviours, uses and tenures-we have seen-can change much quicker than urban morphologies, the change of which has long lead times requiring design, funding, approvals and permissions.

\section{The path ahead}

Whether the cities we have adapted so far are going to be our 'new normal' or just an assemblage of temporary measures is unknown, but local governments will have to retain some drive and keep promoting their local assets and community initiatives alongside supporting more localised economies of production and consumption if they are serious about recovery:

if about everything top-down fragilizes and blocks antifragility and growth, everything bottom-up thrives under the right amount of stress and disorder. The process of discovery (or innovation, or technological progress) itself depends on antifragile tinkering, aggressive risk bearing rather than formal education (Taleb 2012, p. 5).

On the score of unprecedented support by governments to businesses around the world, it will be interesting to see whether an interventionist state will underpin the establishment of viable local alternatives to big business and bland spatial solutions, through financial support as well as through effective measures to promote and sustain more inclusive emerging placemaking. Bottom-up temporal and tactical initiatives are providing the means for many people to adapt their local environment to new needs in quick, flexible and economic ways, and to create and sustain new forms of civic engagement, social interaction and solidarity (Schaller and Guinand 2019; Mehta 2019). These bottom-up 'tinkering' practices are becoming increasingly important in the Global North, given the rising austerity and localism agendas, and provide important lessons for planning and urban design. They call for more adaptable placemaking that can respond to shifting needs and demands. At times, such approaches have met top-down initiatives with positive results, illustrating perhaps the self-adjusting ability of panarchies in what Blecic and Cecchini (2020, p. 184) call a 'space which combines top-down with bottom-up, short and medium term, possibly reversible, modular, even ephemeral, actions'. There might be clear benefits in developing planning and design practices that are not exclusively top-down or bottom-up, but a hybrid of the two (Pissourios 2014), or emerging from the middle (Nonaka 1988; Aelbrecht and Stevens 2019). The creation of community-led practices emerging from the rich interactions between various actors coming from the top, bottom and middle, sharing knowledge and skills, shaping the design process and building and managing the finished public spaces could be supported through the provision of funding and training as well as urban policies designed to be more responsive to temporary and informal spaces and uses.

Upon stepping out of lockdown around the globe, we realise that, while for the last five decades we have built cities efficiency-responding to globalised neo-liberal pressures-resilience has been overlooked (see also Blecic and Cecchini 2020, p. 181). Making urban space more liveable, secure and 'prepared' against pandemics, climate change, local shocks and 'the unknown and unpredictable' (Laboy and Fannon 2016) might require a cultural shift. Decades of just-in-time, tight financial management and technical optimisation have produced 'solutions too precisely suited to the immediate need [which] are also vulnerable to changing social and environmental contexts' (Laboy and Fannon 2016, p. 42). There has been insufficient 'investment of effort $[\ldots]$ to enable recycling and adaptable reuse of buildings in the future, [little] ability to see buildings as valuable and expensive as to not overlook their maintenance' (Laboy and Fannon 2016, p. 49). Moving from a 'disposable' to a 'durable' view (Wang 2003 as in Laboy and Fannon 2016, p. 49) of urban tissues 'implies that building for resilience is also a necessary instrument of transformation of our cultural context, [...]' (Laboy and Fannon 2016, p. 49). An antifragile environment - that gains and improves from stress and change, rejects efficiency and optimisation as well as specialisation in favour of choices that increase individual and community optionality (Blecic and Cecchini 2020, p. 181), allows for 'tinkering, local experimentation and failures' (Blecic and Cecchini 2020, p. 184) — chimes with Ruskin's ideas of buildings blessed by 'the golden stain of time' (Ruskin 1892, p. 340 as in Laboy and Fannon 2016, p. 50), brought about by use and successive adaptation. According to Laboy and Fannon (2016, p. 49), 'a resilience view rejects neutral or generic architecture in favour of architecture that creates meaningful, memorable, adaptable and fluid connections with its context', across systems and at different scales.

Our limited understanding of spatialised behaviours during the pandemic offers a glimpse of an urban future where local public spaces are being celebrated, communities are effective support systems, and local institutions and businesses provide a crucial underpinning for social welfarea world where COVID-19 can be 'the driver of positive 
change' (Banai 2020, p. 5). But alongside progressive views with the potential to lead to radical changes in the way we think of, and design the condition for, urban public life and sociability, there are also regressive scenarios summarised in both citizens' and market actors' behaviours, seeing the return of single occupancy car-based forms of mobilities, of residential sprawl, of empty city centres and altogether retreating to individualistic solutions. On the whole, though, what we know so far about the role of morphological and use features in the pandemic is not enough to warrant substantial shifts from the planning and design principles progressive practitioners and scholars have been actively pursuing in the past three decades. Some (Rooij et al. 2020, p. 1) suggest that 'the crisis actually amplified a debate that was started already before the pandemic: the scale of mixed-use (Hausleitner 2019; Hill 2020), sustainable mobility (Newman et al. 2017) and the meaning of public space (Carmona 2015; Mehta 2014)'. While simple correlations abound and assumptions thrive, there are little concrete and explanatory data to draw from, let alone enough to provide the basis for new directions in the future development of planning and design policy and practice. Much is at stake, though, given the immediacy and pressure brought about by the COVID19-related emergency and as we know, previous pandemics show that city growth does not delay after the emergency (Florida and Pendigo 2020). Where can we start to build a body of evidence for building an environment that can withstand the challenges ahead?

\section{Researching antifragility in the built environment: a progressive research agenda}

Closing, we propose a research agenda to provide a knowledge base to support the development of an antifragile approach to urban design, using GAC to test urban tissues and uses as well as spatialised behaviours in cities. Practically, this means using the pandemic as a springboard: COVID-19 is conceptualised as a stressor, allowing us to examine the interface between the fabric of cities and the behaviour of urban dwellers in space under pressure and to ultimately develop a more resilient planning and design approach that overcomes the fragmented and emergencydriven ad hoc adaptions described earlier. For this we will need to consider the spatial and morphological details in particular, but also step back and review the broader context of planning and urban design interventions and policies, and their effects, to develop antifragile morphologies able to support effective urban resilience. To advance our knowledge we propose the following five steps for a progressive research agenda.

\section{Culturally contextualised embedded case studies}

Traditional studies of resilience, looking at all parts of the system as embedded systems, are important as they expose the complex processes of reciprocal adaptation between their constituent components (Martin and Smiley 2007 as in Martin 2010, p. 14), but they are less effective at drawing attention to the preparedness of individual parts. This is particularly true for the urban environment. We know from past pandemics that an important element of preparedness lies in the built environment, often in features that are difficult to change at speed. As culture is crucial in shaping sociability in space, we need to develop more sophisticated methods to produce contextualised and localised case studies of urban tissues and uses, placing morphological features at the centre of articulated cultural and behavioural spatial templates in order to further our understanding of the role of both macro and micro-spatial features of cities. These cases should be carefully chosen, be interscalar, embedded, looking at the built environment's antifragility, and the GAC of governance and community systems, teasing out how actors relate to the different parts in various 'action arenas' (Hassler and Kohler 2014, p. 125).

\section{Testing GAC and measuring antifragility}

The GAC of systems can be tested through principles. Wildavsky (1988), drawing on Watt and Craig (1986), developed seven principles that resilient systems need to respond to: homeostasis (effective feedback between components), omnivory (availability of subsidiary resources to withstand stress), high flux (relative to the speed of resources mobilised at any given time in aid of recovery), flatness (connections other than hierarchies amongst parts), buffering (excess capacity) and redundancy (overlapping functions) (see also Hassler and Kohler 2014, p. 126). These principles can serve as a nascent analysis framework. Historically, resilience in the built environment disciplines has conceptually focused on tacit design principles looking at the longer range and aiming at oversizing, redundancy and reparability (Hassler and Kohler 2014, p. 119). Others have labelled these resilience criteria as robustness (strength to withstand), redundancy (spare capacity), resourcefulness (capacity to detect and respond) and rapidity (speed of response) (Bruneau et al. 2007; cf. Laboy and Fannon 2016, p. 42). Such categories might be developed further to subsume the antifragile quality of positive evolution and improvement through stress. Examples in Table 1 suggest that size, flexible layout, relational position within systems and multiple-use potential could provide a basis to measure the antifragility of the urban environment. Additionally, the categories Laboy and Fannon (2016, p. 49) proposed as resilience measures can add a temporal dimension: extension adaptability, internal 
adaptability, planning adaptability and testing implementation speed from 'immediate transformational power' to slower gradual adjustments.

Using resilience as an analytical frame enables (1) to appreciate the interscalar complexity of urban embedded systems, their evolutionary nature, the importance of time as a variable and the dynamics of change; and (2) to develop theorisations of resilience from a novel angle, adding to the idea of GAC and its interface with planning. Using antifragility to complement the general concept of resilience helps us to disentangle issues of practice-ready value without losing sight of urban complexity (Fig. 1).

\section{Assessing spatial micro-features and behaviours}

Contextual elements will need to introduce cases, delving into cultural elements affecting social behaviours in space and teasing out those spatial and morphological variables we know bear significance in relation to COVID-19 spread, such as socio-economic features of neighbourhoods and historical pollution levels. Infection numbers mapped per area might be used in order to choose case studies and for scoping the reach of embedded systems to consider, remembering that the use of secondary data needs to be carefully assessed as it is prone to the reliability issues highlighted in the first section of this paper (Table 2).

Cases should be delimited and defined to specific types of spaces (such as those in Table 3), as these provide (O) opportunity for spread, and social behaviours, as the cultural features supporting ( $\mathrm{T})$ transmission of the virus.

As to $(\mathrm{O})$ in space, Table 3 provides a starting point to look at a set of spaces worth of micro-analysis in each cultural situation chosen. Initiatives developed during the pandemic put localities front and centre and particularly local public spaces seem to have acquired a key role in supporting old and new functional, social, recreational and health needs. How social distancing rules have played out in different places and how local public spaces might adjust to provide GAC in the longer term provide fertile research questions. The focus would be markedly on the super-local and the micro-scale.

In order to uncover issues related to $(\mathrm{T})$, the social interface (how different people behave in space, what space they choose, what they do) and related spatial implications need to be incorporated as co-constitutive of how habits merge and settle within specific contexts. Behavioural change would constitute the focus, both with respect to short-term adjustments and more settled long-term approaches to look back as well as to start thinking about the 'new normal'. Little micro-scale data on the past six months are available but retracing recent public life in various parts of the world might be possible through what social media has recorded and anecdotal observations (e.g. blogs) as well as interviews. As for the 'new normal', the world is each spatial researcher's laboratory at the moment.

Fig. 1 Research design

CULTURE

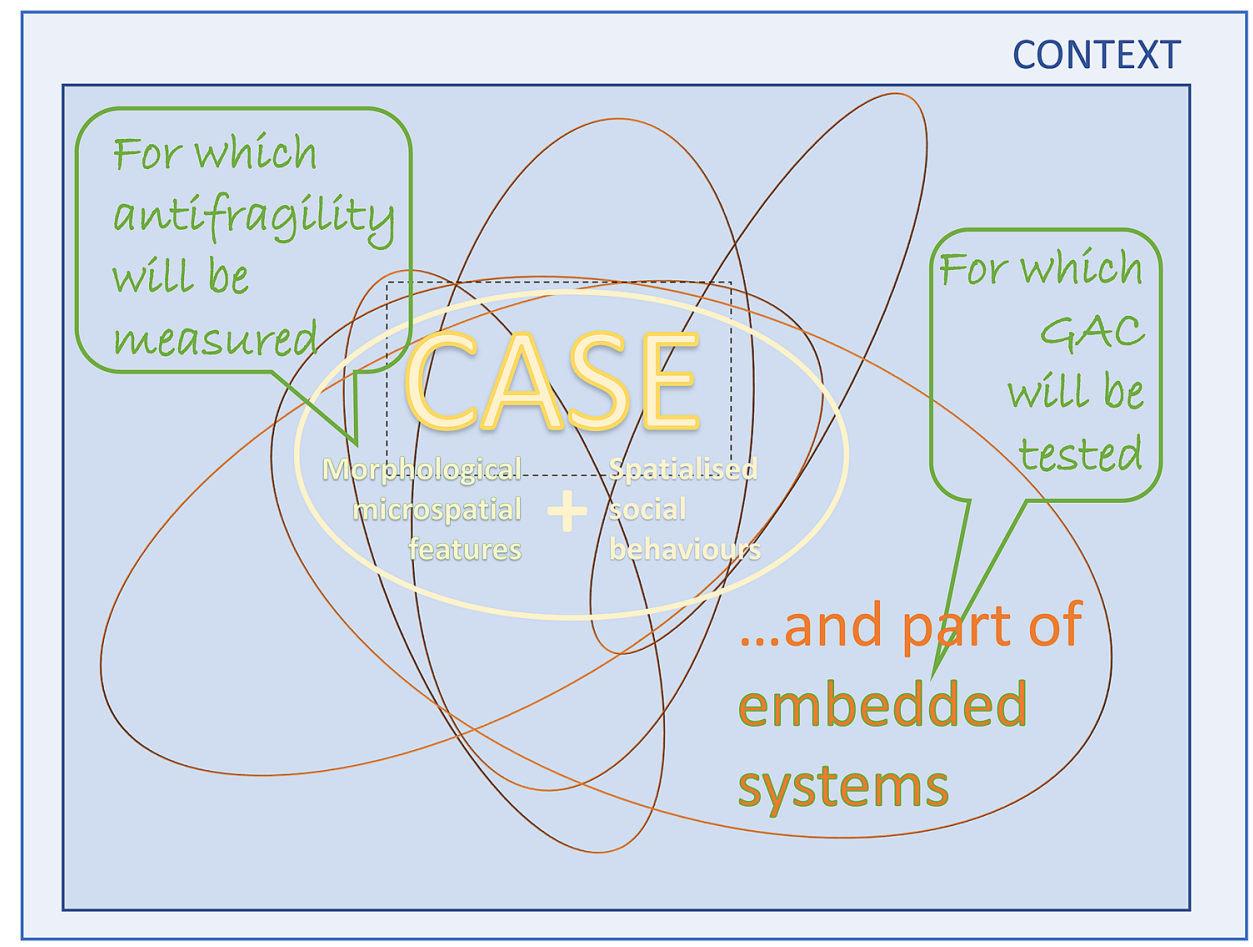




\section{Temporality awareness}

While temporality has often been overlooked in urban design theory and practice, there is an emerging body of knowledge focusing on temporary urbanism and conceptions of temporality (Madanipour 2017) as well as the importance of the 'meanwhile' uses and activities (Bishop \& Williams 2012). Public health emergencies such as the COVID-19 pandemic also provide a unique opportunity for reflection on the productive capacities of temporary urbanism and adaptation by exploring the systematic use of timescales and timeshifts as analytical tools in spatial analysis. Doing so acknowledges the fluidity and malleability of space in time and allows us to take stock of the potential of this in future innovations and adaptations.

\section{A multidisciplinary gaze}

Planning and urban design scholars cannot forego the opportunity to gather substantial knowledge on how the materiality of the city, its scalar, morphological and network features, interacts with the socio-economic and cultural substance of the society that produced and lives in and of it before and during a pandemic. We also need to heed warnings not to lose sight of the 'equally crucial but less immediately visible issues' (Larsson et al. 2020, p. 1) that we have been pursuing in recent decades, such as climate change and social inequalities. We need a research agenda able to develop more sophisticated relational and holistic tools to gather data and to enable work with other professionals (epidemiologists, medical and statistical modellers, natural scientists, etc.) in trying to make sense of both technical and lay insights-in what is a multi-scalar, evolutionary, possibly spatially pathdependent challenge. We ought to develop more appropriate theoretical frameworks by drawing on those available, from resilience to antifragility, to interpret our findings and to understand the city for the complex object it is-not just the product of the here and now but also the setting where the consequences of processes rooted far in both time and space play out with unprecedented immediacy.

COVID-19 casts a different light on the city we know; resetting our research endeavours would enable us to speculate about progressive and regressive routes planning might take post-pandemic but also coincidentally to rethink ways of living together, in tune with each other and the natural world and aware of the fragile natural, anthropic and social balances that sustain us all.

\section{References}

Aelbrecht, P., and Q. Stevens, eds. 2019. Public space design and social cohesion: An international comparison. London: Routledge.
Alexander, D.E. 2013. Resilience and disaster risk reduction: An etymological journey. Natural Hazards and Earth System Sciences 13 (13): 2707-2716.

ATM Citta' Metropolitana. 2020. La mappa dei contagi nel capoluogo, nell'hinterland e nel lodigiano. https://www.facebook.com/giuli ogallera/videos/277074159993086/. Accessed 10.05.2020.

Banai, R. 2020. Pandemic and the planning of resilient cities and regions. Cities 106: 1-6.

Barker, R.G. 1968. Ecological psychology: Concepts and methods for studying the environment of human behavior. Stanford: Stanford University Press.

Bechtel, R.B. 1997. Environment and behavior: An introduction. Thousand Oaks: Sage Publications.

Bechtel, R.B., and A. Churchman. 2002. Handbook of environmental psychology. New York: Wiley.

Berkes, F., and C. Folke. 1998. Linking social and ecological systems: Management practices and social mechanisms for building resilience. Cambridge: Cambridge University Press.

Berkes, F., J. Colding, and C. Folke. 2003. Navigating social-ecological systems: Building resilience for complexity and change. Cambridge: Cambridge University Press.

Bishop, P., and L. Williams. 2012. The temporary city. London: Routledge.

Blecic, I., and A. Cecchini. 2020. Antifragile planning. Planning Theory 19 (2): 172-192.

Bliss, L. 2020. What a coronavirus recovery could look like. Bloomberg City Lab, 23 March 2020. https://www.bloomberg.com/news/ articles/2020-03-23/what-a-coronavirus-recovery-could-look-like. Accessed 19 June 2020.

Bosher, L. 2008. Hazards and the built environment: Attaining built-in resilience. Abingdon: Taylor and Francis.

Bruneau, M., S.E. Chang, R.T. Eguchi, G.C. Lee, T.D. O'Rourke, A.M. Reinhorn, M. Shinozuka, K. Tierney, W.A. Wallace, and D. von Winterfeldt. 2003. A framework to quantitatively assess and enhance the seismic resilience of communities. Earthquake Spectra 19 (4): 733-752.

Calvino, I. 1972. Le citta' invisibili. Turin: Einaudi.

Chelleri, L., J.J. Waters, M. Olazabal, and G. Minucci. 2015. Resilience trade-offs: Addressing multiple scales and temporal aspects of urban resilience. Environment and Urbanization 27 (1): 181-198.

Coaffee, J. 2013. Towards next-generation urban resilience in planning practice: From securization to integrated place making. Planning Practice and Research 28 (3): 323-339.

Conticini, E., B. Frediani, and D. Caro. 2020. Can atmospheric pollution be considered a co-factor in extremely high level of SARSCoV-2 lethality in Northern Italy? Environmental Pollution, 261, June 2020. https://pubmed.ncbi.nlm.nih.gov/32268945/. Accessed 05.05.2020.

Daly, J., K. Dovey, and Q. Stevens. 2020. We can't let coronavirus kill our cities. Here's how we can save urban life. The Conversation. https://theconversation.com/we-cant-let-coronavirus-killour-cities-heres-how-we-can-save-urban-life-137063. Accessed 01.10.2020.

Davoudi, S., E. Brooks, and A. Mehmood. 2013. Evolutionary resilience and strategies for climate adaptation. Planning Practice and Research 28 (3): 307-322.

Dryhurst, S., C.R. Schneider, J. Kerr, A.L.J. Freeman, G. Recchia, A.M. van der Bles, D. Spiegelhalter, and S. van der Linden. 2020. Risk perceptions of COVID-19 around the world. Journal of Risk Research. https://doi.org/10.1080/13669877.2020.17581 93. Accessed 05.10.2020.

Fang, W. and S. Wahba. 2020. Urban density is not an enemy in the Coronavirus fight: Evidence from China. Sustainable Cities: World Bank Blogs. https://blogs.worldbank.org/sustainableciti es/urban-density-not-enemy-coronavirus-fight-evidence-china . Accessed 09.06.2020. 
Florida, R. and S. Pendigo. 2020. Getting urban economies back-up and running after COVID-19: A ten point action plan for economic developers (or economic development organisations). RestoreYourEconomy.org, a project funded by the U.S. Economic Development Administration (EDA). https://restoreyoureconomy.org/ index.php?submenu $=$ Overview $\&$ src $=$ gendocs $\&$ ref $=315 \&$ categ ory=Main. Accessed 30 March 2020.

Folke, C., S.R. Carpenter, B. Walker, M. Scheffer, T. Chapin, and J. Rockström. 2010. Resilience thinking: Integrating resilience, adaptability and transformability. Ecology and Society 15 (4): 20. http://www.ecologyandsociety.org/vol15/iss4/art20/. Accessed 05.10.2020.

Geldsetzer, P. 2020. Knowledge and perceptions of COVID-19 among the general public in the United States and the United Kingdom: A cross-sectional online survey. Annals of Internal Medicine 173 (2): $157-160$.

Ghosh, A., S. Nundy, S. Ghosh, and T.L. Mallik. 2020. Study of COVID-19 pandemic in London (UK) from urban context. Cities 106: 1-9. https://reader.elsevier.com/reader/sd/pii/S026427512 0312762?token=8D629152383CD8E116E95C667220966108C ED6BD94E9E83B657A41A2FAA0B63D52441660B21AE0FA 3C5B63A5717754BB. Accessed 15 Oct 2020.

Gifford, R. 1987. Environmental psychology: Principles and practices. Needham Heights: Allyn and Bacon.

Hamidi, S., S. Sabouri, and R. Ewing. 2020. Does density aggravate the COVID-19 pandemic? Journal of the American Planning Association 86 (4): 495-509.

Hassler, U., and N. Kohler. 2014. Resilience in the built environment. Building Research and Information. 42 (2): 119-129.

Hollands, G.J., I. Shemilt, T.M. Marteau, S.A. Jebb, M.P. Kelly, R. Nakamura, M. Suhrcke, and D. Ogilvie. 2013. Altering microenvironments to change population health behaviour: Towards an evidence base for choice architecture interventions. BMC Public Health 13: 1218. https://doi.org/10.1186/1471-2458-13-1218. Accessed 05.10.2020.

Holling, C.S. 1973. Resilience and stability of ecological systems. Annual Review of Ecology and Systematics 4: 1-23. https://doi. org/10.1146/annurev.es.04.110173.000245. Accessed 03.07.2020

Holling, C.S., and M.A. Goldberg. 1971. Ecology and planning. Journal of the American Institute of Planners 37: 221-230. https://doi. org/10.1080/01944367108977962. Accessed 03.07.2020.

Krause, N.M., I. Freiling, B. Beets, and D. Brossard. 2020. Fact-checking as risk communication: The multi-layered risk of misinformation in times of COVID-19. Journal of Risk Research. https://doi. org/10.1080/13669877.2020.1756385.

Kucharsky, 2020. Adam Kucharski on what should—and shouldn'tWorry us about the coronavirus. TED Talk Bonus. https://www. ted.com/talks/the_ted_interview_adam_kucharski_on_what_ should_and_shouldn_t_worry_us_about_the_coronavirus?langu age $=$ en. Accessed 15 March 2020.

Laboy, M., and D. Fannon. 2016. Resilience theory and praxis: A critical framework for architecture. Enquiry the ARCC Journal for Architectural Research. https://doi.org/10.17831/enq:arcc.v13i2 .405 .

Larsson, N., G. Mangone, M. Berchtold, G. Foliente, H. Delcourt, L. Leighton, J. Cinq-Mars, G. Chaloner-Larsson, W. Kujawski, M.H. Issa, B. Hierlihy, S. Salat, F. Fadli, O.G. Nobre Azevedo, T. Coady, S. Legault, R.B. Borg, L. Braganca, J.P. Carvalho, R. Askar, and A. Edminster. 2020. Pandemics and the built environment, Technical Report. International Initiative for a Sustainable Built Environment, June 2020. http://iisbe.org/system/files/priva te/Covid-19\%20and\%20the\%20Built\%20Environment\%2017S ep20.pdf. Accessed 1.10.2020.

Lee, T. 1976. Psychology and the environment. London: Methuen.

Lynch, K. 1960. The image of the city. Cambridge: MIT Press.
Madanipour, A. 2017. Cities in Time: Temporary urbanism and the future of the city. London: Bloomsbury.

Marcus, L., and J. Colding. 2014. Toward an integrated theory of spatial morphology and resilient urban systems. Ecology and Society 19 (4): 55.

Massey, D. 2005. For space. London: Sage.

Martin, R. 2010. Regional economic resilience, hysteresis and recessionary shocks. In Papers in Evolutionary Economic Geography. Urban and Regional Research Centre, Utrecht University.

Meerow, S., J.P. Newell, and M. Stults. 2016. Defining urban resilience: A review. Landscape and Urban Planning 147 (16): 38-49.

Mehaffy, M. 2020. Why we need sociable distancing. Public Square, A CNU Journal. https://www.cnu.org/publicsquare/2020/03/30/ why-we-need-sociable-distancing. Accessed 20 June 2020.

Mehrabian, A., and J.A. Russell. 1974. An approach to environmental psychology. London: Holt.

Mehta, V. 2019. The street: A fluid place of social cohesion. In Public space design and social cohesion: An international comparison, ed. P. Aelbrecht and Q. Stevens. London: Routledge.

Morbelli, G. 1997. Citta' e piani d'Europa. La formazione dell'urbanistica contemporanea. Bari: Dedalo.

Nathan, M. 2020. The city and the virus. Medium. https://mediu m.com/@maxnathan/the-city-and-the-virus-db8f4a68e404. Accessed 1.10.2020.

Nonaka, I. 1988. Toward middle-up-down management: Accelerating information creation. Sloan Management Review 29 (3): 9-18.

Ogen, Y. 2020. Assessing $\mathrm{NO}_{2}$ levels as a contributing factor to COVID-19 fatality. Science of the Total Environment 726. https:// doi.org/10.1016/j.scitotenv.2020.140672https://doi.org/10.1016/j. scitotenv.2020.139236https://doi.org/10.1016/j.scito tenv.2020.139239https://doi.org/10.1016/j.scitotenv.2020.13985 3. Accessed 20 Oct 2020.

ONS. 2020a. Counts and ratios of coronavirus-related deaths by ethnic group, England and Wales. https://www.ons.gov.uk/peoplepopu lationandcommunity/birthsdeathsandmarriages/deaths/datasets/ countsandratiosofcoronavirusrelateddeathsbyethnicgroupenglan dandwales. Accessed 11.06.2020.

ONS. 2020b. Deaths involving COVID-19 by local area and deprivation. https://www.ons.gov.uk/peoplepopulationandcommunity/ birthsdeathsandmarriages/deaths/datasets/deathsinvolvingcovid 19bylocalareasanddeprivation. Accessed 11.06.2020.

OXFAM. 2020. The hunger virus: How COVID-19 if fuelling hunger in a hungry world. OXFAM Media Briefings, July 2020. https:// oxfamilibrary.openrepository.com/bitstream/handle/10546/62102 3/mb-the-hunger-virus-090720-en.pdf. Accessed: 9.10.2020.

Pissourios, I.A. 2014. Top-down and bottom-up urban and regional planning: Towards a framework for the use of planning standards. European Spatial Research and Policy 21: 83-99.

Pizzo, B. 2015. Problematizing resilience: Implications for planning theory and practice. Cities 43: 133-140.

Porteous, J.D. 1977. Environment and behavior: Planning and everyday urban life. Reading: Addison-Wesley.

Proshansky, H.M., W.H. Ittelson, and L.G. Rivlin. 1972. Freedom of choice and behavior in a physical setting. In Environment and the social sciences: Perspectives and applications, ed. J.F. Wohlwill and D.H. Carson, 29-43. Washington, DC: American Psychological Association.

Pueyo, T. 2020. Coronavirus: The hammer and the dance. What the next 18 months might look like, if leaders buy us time. Medium. https://medium.com/@tomaspueyo/coronavirus-the-hammer-andthe-dance-be9337092b56. Accessed 08.06.2020.

Pykett, J., B. Chrisinger, K. Kalliopi, T. Osborne, B. Resch, A. Stathi, E. Toth, and A. Whittaker. 2020. Developing a Citizen Social Science approach to understanding urban stress and promote wellbeing in urban communities. Palgrave Communications 6 (1): 1-11. 
Rooij, R., K. Aalbers, B. Hausleitner, C. Newton, and R. Rocco. 2020. Education for the resilient city-Teaching and learning urban design and planning in COVID-19 times. In Proceedings of the Institution of Civil Engineers-Urban Design and Planning, August 2020

Rothgerber, H., T. Wilson, D. Whaley, D.L. Rosenfeld, M. Humphrey, A.L. Moore, and A. Bihl. 2020. Politicizing the COVID-19 Pandemic: Ideological differences in adherence to social distancing. Available at file//C:/Users/user/Downloads/PoliticizingtheCOVID-19Pandemic-IdeologicalDifferencesinAdherencetoSocialDistancing.pdf. Accessed 1.10.2020.

Salama, A. 2020. Coronavirus questions that will not go away: Interrogating urban and socio-spatial implications of COVID-19 measures. Emerald Open Research 2 (14). https://emeraldopenresearch. com/articles/2-14/v1. Accessed 03.07.2020.

Schaller, S., and S. Guinand. 2019. Pop-up landscape design and the disruption of the ordinary. In Public space design and social cohesion: An international comparison, ed. P. Aelbrecht and Q. Stevens. London: Routledge.

Seale, H., A.E. Heywood, J. Leask, M. Sheel, S. Thomas, D.N. Durrheim, et al. 2020. COVID-19 is rapidly changing: Examining public perceptions and behaviors in response to this evolving pandemic. PLoS ONE 15 (6): e0235112. https://doi.org/10.1371/journ al.pone.0235112. Accessed 20 Oct 2020.

Sennett, R. 2020. 100 Day Studio: Richard Sennett-Density in the wake of social distancing. https://www.youtube.com/ watch? $\mathrm{v}=\mathrm{gxMd}$ OfwGMTk. Accessed 15 April 2020.

Singer, M. 2009. Introducing syndemics: A critical systems approach to public and community health. New York: Wiley.

Spaans, Marjolein, and Bas Waterhout. 2017. Building up resilience in cities worldwide-Rotterdam as participant in the 100 Resilient Cities Programme. Cities 61: 109-116.

Spinney, L. 2017. Pale rider. The Spanish flu of 1918 and how it changed the world. London: Vintage (Penguin Random House).

Taleb, N.N. 2012. Anti-fragile. Things that gain from disorder. London: Penguin Books.

Taleb, N.N., and R. Douady. 2013. Mathematical definition, mapping and detection of (anti)fragility. Quantitative Finance 13 (11): $1677-1689$.

Tierney, K.J., and M. Bruneau. 2007. Conceptualizing and measuring resilience: A key to disaster loss reduction. Emmitsburg: National Emergency Training Center.

Tran, V.-T., and P. Ravaud. 2020. COVID-19-related perceptions, context and attitudes of adults with chronic conditions: Results from a cross-sectional survey nested in the ComPaRe e-cohort. PLoS ONE 15 (8): e0237296. https://doi.org/10.1371/journ al.pone.0237296. Accessed 27 Sep 2020.

Travaglio, M., Y. Yu, R. Popovic, N.S. Leal, and M. Martins. 2020. Links between air pollution and COVID-19 in England (preprint). https://doi.org/10.1101/2020.04.16.20067405v5. Accessed 05.05.2020.
Truelove, S., O. Abrahim, C. Altare, S.A. Lauer, K.H. Grantz, A.S. Azman, and P. Spiegel. 2020. The potential impact of COVID-19 in refugee camps in Bangladesh and beyond: A modelling study. PLoS Medicine. https://doi.org/10.1371/journal.pmed.1003144.

United Nations Environment Programme. 2020. Zoonotic diseases and how to break the chain of transmission. Nairobi: UNEP Frontiers Report Series.

Valentine, G. 2008. Living with difference: Reflections on geographies of encounters. Progress in Human Geography 32 (3): 323-337.

Valentine, G., and L. Waite. 2010. Negotiating difference through everyday encounters: The case of sexual orientation and religion and belief. Antipode 44: 474-492.

Watt, K.E., and P.P. Craig. 1986. System stability principles. Systems Research 3 (1986): 191-201.

Weinreb, A.R., and Y. Rofè. 2013. Mapping feeling: An approach to the study of emotional response to the built environment and landscape. Journal of Architectural and Planning Research 30 (2): $127-145$.

Wildavsky, A. 1988. Search for safety. New Brunswick: Transaction Publishers.

Williams, S.N., C.J. Armitage, T. Tampe, and K. Dienes. 2020. Public perceptions and experiences of social distancing and social isolation during the COVID-19 pandemic: A UK-based focus group study. British Medical Journal Open 10: e039334. https://doi. org/10.1136/bmjopen-2020-039334.

Wilson, H. 2017. On geography and encounter: Bodies, borders and difference. Progress in Human Geography 41 (4): 451-471.

Wong, C.M.L., and O. Jensen. 2020. The paradox of trust: Perceived risk and public compliance during the COVID-19 pandemic in Singapore. Journal of Risk Research. https://doi. org/10.1080/13669877.2020.1756386.

World Bank. 2020. Tackling COVID-19 (coronavirus) with water, sanitation and hygiene in DRC. World Bank Feature Story. https ://www.worldbank.org/en/news/feature/2020/04/20/tacklingcovid-19-coronavirus-with-water-sanitation-and-hygiene-in-drc. Accessed 20 June 2020.

WHO. 2020. Strengthening preparedness for COVID-19 in cities and other urban settings: Interim guidance for local authorities, Geneva: World Health Organization. https://apps.who.int/iris/ handle/10665/331896. Accessed 20 Oct 2020.

Wu, X., R.C. Nethery, B. Sabath , D. Braun, and F. Dominici. 2020. Exposure to air pollution and COVID-19 mortality in the US: A national cross-sectional study (preprint). https://doi. org/10.1101/2020.04.05.20054502v2. Accessed 05.05.2020.

Zeisel, J. 2006. Inquiry by design: environment/behavior/neuroscience in architecture, interiors, landscape and planning. New York: Norton.

Publisher's Note Springer Nature remains neutral with regard to jurisdictional claims in published maps and institutional affiliations. 